\title{
LOS REQUISITOS DE LA LEX AQUILIA, CON ESPECIAL REFERENCIA AL DAÑO. LECTURAS DESDE LAS DISTINTAS TEORÍAS SOBRE EL CAPÍTULO TERCERO *
}

\author{
Cristián Aedo Barrena**
}

\begin{abstract}
RESUMEN
El presente trabajo tiene por objeto hacer un breve repaso de los requisitos que la lex Aquilia exigía para su concurrencia, desde las distintas lecturas que la doctrina romanista moderna ha hecho del capítulo tercero. Así, se muestra de que manera las distintas posiciones influyen en la conceptualización de la iniuria, en el desarrollo decretal y, por consiguiente en la relación de causalidad, pero especialmente en el daño, que es el requisito al cual la investigación presta más atención. Así se analiza, según estas diferentes visiones, el desarrollo del principio id quod interest. Claramente, como se ha insinuado en este resumen, se enfrentan dos visiones contrapuestas, entre aquellos que ven en la lex Aquilia un estatuto originariamente resarcitorio (negando incluso el principio corpore corpori y adjudicándolo a la interpretación medieval) versus un punto de vista que considera que la ley tenía originariamente un carácter estrictamente penal, derivando paulatinamente hacia un carácter resarcitorio. En el primer punto de vista, el principio id quod interest se presentó desde un comienzo en el capítulo tercero, el que exclusivamente se refería al daño (tesis de Daube); desde el segundo punto de vista, la interpretación permitió la evolución desde el premium corporis hasta el principio id quod interest, en el punto de vista afirmado desde Jolowicz y recientemente sustentado por Valditara.
\end{abstract}

* Trabajo recibido con fecha 23 de octubre de 2008, y aprobado el 3 de marzo de 2009.

** Abogado. Profesor de Derecho civil de la Universidad Católica del Norte, Antofagasta. Diploma de Estudios Avanzados y Doctor (C) por la Universidad de Deusto. Becario del proyecto Mecesup UCN 0301. Correo electrónico: caedo@uc.cl 


\begin{abstract}
This paper aims to make a brief review of the requirements that the lex Aquilia required for its concurrence, from the various readings that the modern Roman law doctrine has made the third chapter. Thus, it shows how the different positions that influence the conceptualization of iniuria, in the development decretal, and therefore in terms of causality, but especially in the damage, which in that part of that research pays more attention. So is analyzed, as these various visions, the development of the principle id quod interest. Clearly, as has been hinted in this summary, they face contrasting two visions, between those who see the lex Aquilia a statute originally damages (including the principle corpore corpori and awarded to the medieval interpretation) versus a viewpoint that believes that the law was originally a purely criminal, gradually drifting towards compensation. In the first view, the principle id quod interest was presented from the beginning in the third chapter, which only covered the damage (thesis Daube); from the second view, the interpretation enabled the evolution from the premium corporis until the beginning id quod interest, in point of view, and recently said from Jolowicz supported by Valditara.
\end{abstract}

PALABRAS CLAVES

Lex Aquilia-acciones-requisitos de la ley- iniuria- causalidad- culpa- daños-id quod interest

KEY WORDS

Lex Aquilia-actions-requirements of the law-iniuria-causality-fault-damage-id quod interest

1. El capítulo tercero como instrumento para la comprensión del problema de los requisitos de la lex Aquilia y especialmente del daño aquiliano: las distintas visiones.

Como se sabe, la lex Aquilia correspondió a un plebiscito rogado por el tribuno Aquilio, cuya datación es imprecisa, aunque parece remontarse al siglo III a.C. ${ }^{1}$ Constaba de tres

La verdad es que hay una amplia discusión en relación con la datación de la ley, a la que no podemos referirnos en este trabajo. En principio, aunque la ley se refiere a un tribuno Aquilio, el dato no es del todo preciso, pues hay varios. Sobre esta cuestión, véase, por todos, a Corbino, Alessandro, Il danno qualificato e la lex Aquilia, Milán: Cedam, 2005, p 31. Según Cannata, Carlo Augusto, "Sul testo originale della lex Aquilia: premesse e ricostruzione del primo capo", $S D H I$, No 58, 1992, p 199 y ss el probable autor de la lex haya sido P. Aquilius, tribuno de la plebe, quien habría vivido alrededor del año 210 a.C. En lo que respecta a la discusión de la datación, el sector mayoritario se inclina por el año 286 a.C o el año 287 a.C. Hay otros que la fijan en el año 186 a.C.; e, incluso, otros piensan que de manera indeterminada puede ser fijada en el siglo III a.C. Para el análisis 
Los requisitos de la lex Aquilia, con especial referencia al daño.

Lecturas desde las distintas teorías sobre el capítulo tercero.

capítulos. En el primero, se establecía que quien mataba injustamente a un esclavo, un cuadrúpedo o una cosa inanimada, debía pagar al dueño el más alto valor de la cosa dentro del año anterior al acto dañoso. ${ }^{2}$ El segundo capítulo se refería a un supuesto totalmente diverso, pues sancionaba al adstipulor (acreedor conjunto) que daba por pagada la deuda en perjuicio o fraude del acreedor principal. ${ }^{3}$

Finalmente, el problemático capítulo tercero se encuentra mencionado en dos pasajes. En D. 9, 2, 27, 5 y en Gayo 3, 217. ${ }^{4}$ Es imposible reseñar con detalle en este trabajo la enorme

de este problema puede consultarse, entre otros, a Biscardi, Arnaldo, "Sulla data della "lex Aquilia", A.A.V.V. Scritti in Memoria di Antonino Giuffrè. Tomo I, Milán: Giuffrè, 1967. Guarino, Antonio, "La data della lex Aquilia", LABEO, No 14, 1968. Zimmermann, R, The Law of Obligations. Roman Fundations of the Civilian Tradition, Oxford, 1996, pp 955 y ss. Cannata, Carlos Augusto, "Il terzo capo della "Lex Aquilia", BIDR, Nos 98-99, 1995-1996, p 132.

$2 \quad$ En el D. 9, 2, 2pr se señala: "Lege Aquilia capite primo cavetur ut qui servum servamve alienum aliemnamve quadrupedem vel pecudem iniuria occiderit, quanta id in eo anno plurimi fuit, tantum aes dare domino damnas esto" ("Por el primer capítulo de la ley Aquilia se prevé "que quien matare injustamente a un esclavo o esclava ajenos o aun cuadrúpedo o a una res, sea condenado a dar al dueño el valor máximo que tuvo aquél año”). Para la versión en latín, seguimos a Mommsen, Theodorus. Krueger, Paulus, Corpus Iuris Civile, Volumen Primum, Instituciones. Digesta, Hildesheim: Weidmann, 1988. Para la versión en castellano, D’ors, Alvaro. Hernández Tejeiro, F. Fuenteseca, P. García Garrido, M. Burillo, J, El Digesto de Justiniano, Pamplona: Aranzadi, 1968. Los pasajes que en adelante se citen corresponden a estas versiones.

En Gayo 3,215 también se le menciona, en los siguientes términos: "Damni iniuriae actio constituitur per legem Aquiliam, cuius primo capite, cautum est, ut si quis hominem alienum alienamve quadrupedem quae pecudum numero sit iniuria occiderit, quanta ea res in eo anno plurimi fuit, tantum domino dare damnas esto" ("La acción de daño injusto es establecida por la ley Aquilia, en cuyo primer capítulo se dispone que si alguien mata injustamente un esclavo ajeno o un cuadrúpedo ajeno de cualquier clase de ganado, sea condenado a dar al dueño el mayor valor que esa cosa haya tenido en aquel año"). El texto, tanto en latín como en castellano, ha sido tomado de Hernández Tejero, Francisco. (Coord). Abellan Velasco, Manuel. Arias Bonet, Juan Antonio. Iglesias Redondo, Juan. Roset Esteve, Jaime, Instituciones de Gayo. Edición bilingüe, Madrid: Civitas, 1985. Las referencias sucesivas estarán basadas en esta obra.

Sobre las discusiones existentes en relación con el capítulo, vease Natali, Nuncio, La lege Aquilia ossia il damnum iniuria datum, Roma: L'erma di Bretschneider, 1970, pp 23-24 y Cannata, Carlo Augusto, Sul problema della responsabilità nel Diritto Privato Romano, Catania: Librería Editriche Torre Catania, 1996, p 212.

3 El Digesto sólo le dedica el pasaje contenido en D. 9, 2, 27, 4 para destacar que cayó posteriormente en desuso: "Huius legis secundum quidem capitulum in desuetudinem abiit" ( "El segundo capítulo de esta ley cayó en desuso"). La otra fuente es la del pasaje gayano 3, 215: “Capite secundo 〈adversus〉 adstipulatorem qui pecuniam in fraudem stipulatoris acceptam fecerit, quati ea res est, tanti actio constituitur" ("En el segundo capítulo se establece una acción contra el coestipulante que se hubiera dado por pagado en fraude del estipulante"). Sobre los problemas relativos a este capítulo, especialmente los esfuerzos por buscar una base común con los otros dos capítulos, puede consultarse a Cannata, Carlo Augusto, "Considerazioni sul testo e la portata originaria del secondo capo della "lex Aquilia", Index, No 22, 1994; y, Grosso, Giuseppe, "La distinzione fra "res corporales" e "res incorporales" e il secondo capo della lex Aquilia", A.A.V.V. Synteleia Vicenzio Arangio Ruiz. Napolés: Editore Jovene Napoli, 1964.

$4 \quad$ En el primero, se señala: "Tertio autem capite ait eadem lex Aquilia: "Certerarum rerum praeter hominem et pecudem occisos si quis alteri damnum faxit, quod usserit fregerit ruperit iniuria, quanta ea res erit (fuit) in iebus triginta proximis, tantum aes domino dare damnas esto" ("La misma ley Aquilia dice en el tercer capítulo: "respecto de las demás cosas, sea de esclavo y res que hayan sido muertos, si alguien hiciere daño a otro 
discusión que existe en esta materia, pero el propósito de resumirla, brevemente, es la incidencia que tiene en la materia en análisis, como luego veremos.

En efecto, en el capítulo tercero establecía que en caso que el daño proviniera de una conducta que consistiera en quemar, quebrar o romper (urere, frangere, rumpere), se debía indemnizar con el valor que la cosa hubiese tenido dentro del período de los 30 días. La cuestión es que no está claro el período dentro del cual debía ser considerada dicha sanción. El pasaje de Gayo 3, 218 utiliza la expresión fuerit y en el D. 9, 2, 29, 8, se emplea la palabra fuit. Ambos verbos son indicativos que la sanción tendría que haber sido empleada hacia el pasado, entendiéndola dentro de los 30 días anteriores al daño. Como desde este punto de vista habría una equiparación completa con el capítulo primero, también queda lógicamente explicada la indicación del mismo D. 9, 2, 29, 8, con arreglo al cual debía ser considerado en el capítulo tercero la expresión plurimi, es decir, que la indemnización, cualquiera sea el perjuicio inferido, debía comprender el más alto valor de la cosa.

El problema es que dichos pasajes se contradicen aparentemente con el texto del D. 9, 2, 27, 5, que utiliza la partícula erit, en cuyo caso la sanción debía ser entendida como dentro de los 30 días siguientes. Tales contradicciones han dado lugar a las más variadas teorías. En principio y para efectos de este trabajo, siguiendo a MacCormack tales tesis pueden agruparse en $4:^{5}$ a) que en el tiempo que la ley fue aprobada, así como en el derecho clásico, el demandante no recibía el más alto valor del esclavo o de la cosa dañada, sino que el juez valoraba la pérdida por referencia a dicho más alto valor, dentro de los 30 días precedentes al acto que causa el daño. Ésta correspondería a la tesis de Monro; b) que el tercer capítulo, al tiempo de su promulgación, sólo trataba la destrucción de objetos inanimados y proveía como sanción el más alto valor dentro de los 30 días precedentes a la causa del perjuicio. Ésta es la tesis de

porque hubiere quemado, quebrado o roto injustamente, sea condenado a dar al dueño el valor que la cosa alcance en treinta días próximos"). En cuanto al texto gayano: "Capite tertio de omni cetero damno cauetur. Itaque si quis seruum uel eam quadrupedem, quae pecudum numero est <vulneraverit siue eam quadrupedem, quae pecudum numero non est $>$, uelut canem, aut feram bestiam, uelut ursum, leonem uulnauerit uel occiderit, hoc capite actio constituitur. In ceteris quoque animalibus, item in omnibus rebus, quae anima carent, damnum iniuria datum hac parte uindicartur. Si quid enim ustum aut ruptum aut fractum <fuerit>, action hoc capite constituitur, quamquam potuerit sola rupti appellation in omnes istas causas sufficere; ruptum <enim intellegitur, quod quoquo modo corruptum > est; unde non solum usta (aut rupta) aut fracta, sed etiam scissa et colissa et effusaet quoquo modo uitiata aut perempta atque deteriora facta hoc uerbo continentur" ("En el tercer apartado se prevé todo sobre otro tipo de daño: si alguien o matara a un esclavo, o una pieza de ganado, o incluso no de ganado; por ejemplo un perro, o una fiera, oso o león. También castiga esta parte de la ley el daño causado injustamente a cualquier otro animal o cosa inanimada. Hay pues, acción para el caso de que algo fuera quemado, roto o estropeado, aunque para ello basta con la denominación de "roto", ya que se entiende que dentro de lo roto está incluida cualquier cosa que fuera estropeada de otro modo. Por lo tanto, se incluyen dentro de esta palabra las cosas quemadas, rotas, partidas, golpeadas, derramadas, y todas las que hayan sido estropeadas, destruidas o deterioradas").

$5 \quad$ MacCormack, Geoffrey, "On the third chapter of the lex Aquilia”, The Irish Jurist, № 5, 1970, p 165. 
Los requisitos de la lex Aquilia, con especial referencia al daño.

Lecturas desde las distintas teorías sobre el capítulo tercero.

Jolowicz; c) que el tercer capítulo, al tiempo de su promulgación, se refería sólo a las heridas de los esclavos y del ganado, de modo que el demandante podía recuperar las consecuencias de dichas heridas, dependiendo de la evolución de éstas, fijándose el período de los 30 días siguientes al acto dañoso. Es la teoría opuesta a Jolowicz, defendida, como se sabe, por Daube; d) según una cuarta teoría, sustentada por Illife, entre otros, el capítulo tercero, al tiempo de su promulgación, se refería a las más serias heridas y daños causados al esclavo y ganado, así como a objetos inanimados, respectivamente, estableciendo como sanción el más alto valor dentro de los 30 días anteriores a la comisión del ilícito.

Nosotros entendemos que las posiciones doctrinales básicamente pueden agruparse en las signadas con las letras a) y b), es decir, los modelos de Monro y Jolowicz dentro de un grupo, como opuestos a Daube. ${ }^{6}$ Fuera de estas dos tesis antagónicas, a nuestro juicio hay un tercer grupo, en el que pueden agruparse autores que aportan tesis intermedias o derechamente escépticas, como Iliffe, hasta aquellos que desarrollan opiniones propias, como Valditara, equidistante de ambas, quien considera el capítulo tercero como un módulo general de daños. Finalmente, Kelly es quien presenta la aproximación que juzgamos más original, pues estima que el período de 30 días no fue establecido para la valoración o cálculo de la indemnización, sino que, asocia el plazo con el tiempo durante el cual debía pagar la indemnización, antes de ser ejecutado por la manus iniectio. ${ }^{7}$

La mayoría de los autores considera que la sanción estaba referida hacia el pasado; entre otros y por todos, Jolowicz, H.F, "The original scope of the lex Aquilia and the question of damages", $L Q R, \mathrm{~N}^{\mathrm{o}} 38,1922$, pp 220 y ss. Van Warmelo, Paul, "A propos de la loi Aquilia”, RIDA, № 27, 1980, pp 345-348. MacCormack, On the third..., cit n. 5, pp 165 y ss. Más recientemente, CANNATA, Il terzo capo..., cit n 1, pp 120 y ss. También en Cannata, Sul problema..., cit. n. 2, pp 109-110. Gran parte de estos autores consideran que la otra tesis, de Daube, se funda en un error de trascripción del texto de Ulpiano en D. 9, 2, 27, 5, que contendría erróneamente la expresión erit, pero el trabajo más profundo en esta línea sin duda alguna pertenece a Ankum, Hans, "Quanta ea res erit in diebus XXX proximis dans le troisième chapitre de la lex Aquilia: un fantasme florentin" en A.A.V.V. Mélanges en Hommagea Jacques Ellul. Religión, société et politique, París: Press Universitaires de France, 1983, pp 179 y ss, explicando que la expresión se debe a un error del manuscrito Florentino.

En cuanto a la doctrina contraria, fue promovida por Daube, David, "On the third chapter of the lex Aquilia", LQR, N ${ }^{\circ}$ 52, 1936, pp 253-255 y en Daube, David, Roman Private law. Linguistic, social and philosophical aspects, Edimburgo: Edinburgh University Press, 1969, pp 66 y ss. Le siguen, entre otros, Cardiasca, G, "La portée primitive de la Loi Aquilia" en A.A.V.V. Daube Noster. Essays in legal history for David Daube, Edimburgo: Scottish Academic Press, 1974, p 62 y Watson, Alan, The law of obligations in the later Roman republic, Londrés: Clarendon Press, 1965, p 235 y en Watson, Alan, Roman Private Law around 200 BC, Edimburgo: Edinburgh University Press, s.d., p 153, sostiene que la teoría de Daube es la más satisfactoria en relación con el carácter originario del capítulo tercero.

7 La tesis escépticas o bien que se apartan de las otras dos han sido sustentadas, entre otros, por los siguientes autores. Para Iliffe, "Thirty days hath lex Aquilia", RIDA, $3^{\mathrm{a}}$ serie, Tomo V, 1958, pp 496 y ss, aún cuando la tesis de Daube es la más satisfactoria explicación para el capítulo tercero, por cuanto, a diferencia del carácter penal del primero, éste tendría por objeto permitir una adecuada valoración de las heridas, frente a la ausencia de listas o periódicos que fijaran listas de mercado, a diferencia del autor inglés estima que la lex desde un comienzo incluía tanto a los seres animados como inanimados y que en ambos casos la valoración cumplía el mismo papel. Pugsley, David, "On the lex Aquilia and culpa”, TR, № 50, 1982, pp 1-6 considera que los juristas 
Estas teorías sobre el capítulo tercero son en verdad dos maneras distintas de comprender la ley. Las discusiones sobre el capítulo tercero son fundamentales para determinar el carácter originario de la ley y su desarrollo, de ahí que a nuestro juicio resulte justificado detenerse especialmente en esta cuestión. Desde luego, hay numerosísimos puntos de contacto entre las diferentes teorías, pero también muchas son las diferencias. Estas visiones influyen sobre el desarrollo pretoriano de los verbos, sobre las diferencias en la forma en la que se entiende la valoración de los perjuicios, la consagración y la evolución de la fórmula id quod interest, además de las vinculaciones de la lex Aquilia con los delitos anteriores, tratándose de los verbos del tercer capítulo y su equivalencia o no con los delitos de iniuria de las XII Tablas.

Como fuere, desde nuestro punto de vista, la lex Aquilia nace como mecanismo de protección del propietario, quien frente a la destrucción de la cosa no podía recurrir a la acción real emanada del dominio o rei vindicatio -que exigía la existencia actual de la cosa-, de manera que el dueño podía intentar, antes de la lex Aquilia, una actio furti, ampliando la interpretación de la misma. ${ }^{8}$ Por esta razón, al menos originariamente, la acción se establece en favor del propietario una acción personal que le permitía obtener un crédito por el valor de

clásicos utilizaron la sanción hacia al pasado, al igual que en el capítulo primero, pero rechaza su fundamentación en el pretendido carácter penal de la lex, considerando que dicho período tenía por función determinar el valor de acuerdo al costo o valor de contratación de los esclavos o bienes animados heridos, lo que constituiría una gran mejora en relación con penas fijadas en las XII Tablas. Kelly, John, "The meaning of the lex Aquilia", $L Q R, N^{\circ} 80,1964$, pp 82 y ss y Kelly, John, "Further reflections on the lex Aquilia" en A.A.V.V. Studi in onore di Edoardo Volterra, Volumen primero, Milán: Giuffrè Editore, 1971, pp 235-239, propone una nueva reconstrucción del capítulo. En efecto, según su opinión, en el pasaje de Ulpiano en D. 9, 2, 27, 5 podía ser sustituida la expresión "damnum faxit" por "iniuria faxit", extrayendo la palabra iniuria desde su ubicación posterior a sus verbos (que al autor no le parece original) y luego separando la frase de la siguiente manera: "Si quis alteri iniuriam faxit// quod usserit fregerit ruperit // quati ea res erit // in diebus XXX proximis tantum aes dare damnas esto", para arribar a la consecuencia de que el período estuvo ligado a la manus iniectio y no directamente a la valoración de pérdidas.

Finalmente, Valditara, Giuseppe, "Damnum iniuria datum", A.A.V.V.: Derecho Romano de obligaciones. Homenaje al profesor José Luis Murga Gener. Madrid: Centro de Estudios Ramón Areces, 1994, pp 822 y ss, criticando ambas posiciones (más exactamente las de Daube y Jolowicz-Cannata), estima que la valoración era hacia el pasado (pues la partícula erit utilizada en D. 9, 2, 27, 5 se debería a un error de trascripción) y además dicha valoración comprendía tanto a los bienes inanimados como animados, erigiéndose el capítulo tercero en una cláusula general de daños. Una mayoría de autos italianos siguen esta línea, con la excepción de Cannata.

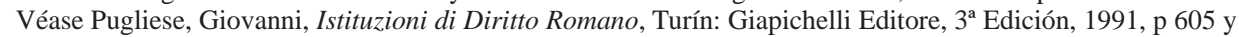
Biondi, Biondo, Istituzioni di Diritto Romano, Milán: Giuffrè Editore, 4 a Edición, 1965, pp 528-531.

8 Sin embargo, esta acción presentaba el inconveniente de exigir el dolo del demandado, a diferencia de la acción de la lex Aquilia, en la que la palabra iniuria de la ley fue interpretada ya por la primera jurisprudencia clásica en el sentido que se debía responder también por ciertos actos de negligencia que causaban daños a otras personas. En este sentido, D’ors, Alvaro, Derecho Privado Romano, Pamplona: Ediciones Universidad de Navarra, $9^{a}$ Edición, 1997, p 436, sin perjuicio de las discusiones de la iniuria, que se verán en los párafos siguientes. Un ejemplo de la ampliación de la acción de hurto en los casos de destrucción de bienes o de la lex Aquilia, puede encontrarse en el pasaje del D. 9, 2, 27: "Si servus servum alienum subripuerit et occiderit, Iulianus et Celsus scribunt et furti et damni iniuriae competere actionem" ("Si un esclavo hubiera raptado y asesinado a un esclavo ajeno, Juliano y Celso escriben que compete la acción de hurto y la de daño injusto”). 
Los requisitos de la lex Aquilia, con especial referencia al daño.

Lecturas desde las distintas teorías sobre el capítulo tercero.

la cosa destruida y por eso algunos autores afirman el carácter instrumental de la acción penal, que no se traducía únicamente en una finalidad sancionadora. ${ }^{9}$ No deja de tener sentido entonces que Shom considere que la acción aquiliae es una acción derechamente reipersecutoria, aunque por el carácter especial que en ella adopta la tasación del daño, ofrezca cierto matiz penal, ${ }^{10} \mathrm{y}$, que la circunstancia que la ley se concediera sólo al propietario, revela su inspiración fundamentalmente resarcitoria. ${ }^{11}$

\section{Los requisitos del delito: una lectura desde el tercer capítulo de la lex Aquilia}

Como primera cuestión, digamos que los autores están de acuerdo en que la lex Aquilia exigió, al menos, los siguientes requisitos para configurar la acción: a) una conducta comisiva; b) la relación de causalidad entre la conducta y el daño; c) el daño; d) la iniuria y la culpa. $^{12}$

9 Entre otros, Valditara, Damnum iniuria..., cit n 7, pp 878-879 y Castresana, Amelia, Nuevas lecturas de la responsabilidad aquiliana, Salamanca: Ediciones Universidad de Salamanca, 2001, p 27. Esta relación entre la lex Aquilia y la propiedad ha sido muy bien visualizada por Corbino, cit n. 1, pp 8 y 9, quien señala que la acción de damnum derivaba de la lesión a un derecho real, distinto de la lesión a un derecho de obligación o personal. Más adelante agrega: "Il principio generale da esi osservato è stato che mentre la lesione di un diritto reale poteva dare luogo non solo ad una rei persecutorio (al diritto di pretendere cioè la reintegrazione nella situazione patrimoniale lesa), ma anche -ricorrendo taluni presupposti (come fu presto per il furtum, ma poi anche per una serie di altri fatti)- ad una "poena" (al diritto di pretendere cioè che l'autore della lesione subisse un'afflizione patrimoniale, talore fissa, talora invece proporzionata alla gravità del fatto e perciò fissata ora nella misura del valore della cosa-simplum- ora in quella di un múltiplo di esso: duplum, triplum, etc.), la violazione di una obbligazione non poteva ricevere altra sancione che la rei persecutio".

10 Shom, Rodolpho, Instituciones de Derecho Privado Romano. Historia y sistema (Traducción de la 17ª edición del alemán por W. Roces), Madrid: Revista de Derecho Privado, 1927, pp 420 y 421.

11 Díaz Bautista, Antonio, "La función reipersecutoria de la poena ex lege Aquilia" en A.A.V.V. La responsabilidad civil de Roma al Derecho moderno, Burgos: Ediciones Universidad de Burgos, 2001, pp 272 y ss. También sobre el tema, muy brevemente, Díaz Melián de Hanisch, Mafalda, "Breve génesis del deber de responder. La esencia de la responsabilidad civil" en A.A.V.V. La responsabilidad civil de Roma al Derecho moderno, Burgos: Ediciones Universidad de Burgos, 2001, cit, p 289 y con un desarrollo más profundo de las posiciones clásicas en la materia, pero referidas a las penas privadas en general, Fuenteseca Degeneffe, Margarita, El delito civil en Roma y en el Derecho español, Valencia: Tirant Lo Blanch, 1997, pp 118 a 126. Sobre el carácter original del texto de la lex y las posibles alteraciones de éste, puede consultarse, con la bibliografía consultada a Zilioto, Paola. L'imputazione del danno aquiliano. Tra iniuria e damnum corpore datum, Padova: Cedam, 2000, pp 45, en nota 8. Sobre el mismo tema, Cannata, Carlos Augusto, "Delito y obbligazione" en A.A.V.V. Illecito e pena privata in etá republicana, Napolés: Edizioni Scientifiche Italiane, 1992, pp 37 a 39; Cannata, Sul problema..., cit n. 2, p 8.

12 Buena parte de los autores considera que estos son los requisitos que emanaban de la lex aquilia. Por todos, se puede citar a D’ors, cit n. 8, p 426, 427 y 436. García Garrido, Manuel, Derecho Privado Romano. Casos,

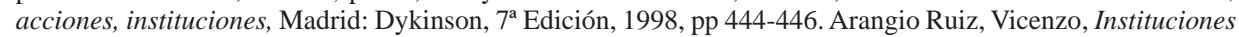
De Derecho Romano (Traducción de la $10^{\text {a }}$ edición italiana por José Caramés Faro), Buenos Aires: Editorial

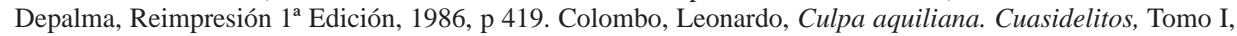
Buenos Aires: Ediciones La Ley, $3^{\text {a }}$ Edición actualizada, 1965, p 70, aún cuando este último autor no menciona la relación de causalidad. 
Ahora bien, es conocido que un principio fundamental en la lex Aquilia, desde el cual pueden deducirse los presupuestos o requisitos y su medida, es el denominado corpore corpori datum. Sobre esta cuestión, con gran acierto, comenta Arangio Ruiz que: “El daño previsto por la lex Aquilia es solamente el causado corpore corpori, es decir, el producido con el esfuerzo muscular del delincuente a la cosa considerada en su estructura física. La sanción de la ley no tiene lugar, en consecuencia, por falta de daño corpore, si se encierra el ganado en un establo para hacerlo morir de hambre, o si se persuade a un esclavo de que suba a un árbol, ocasionándole de esa manera la caída y muerte (Gayo, III, 219)". ${ }^{13}$

De esta manera, en cuanto a la conducta, tipificada en los verbos occidere, para el primer capítulo y urere, frangere y rumpere para el tercero, ampliado posteriormente a corrumpere o quasi corrumpere, según las posiciones, el texto original de la lex Aquilia sólo comprendía las conductas comisivas en atención al principio damnum corpore datum; pero, por la vía pretoria se fueron admitiendo excepciones a la exigencia que el daño debía ser causado mediante una acción, para admitir la posibilidad de daños provocados mediante omisiones. ${ }^{14}$ Por eso, Chironi

13 Arangio, Instituciones..., cit, n. 12, p 418. Trata especialmente el principio del damnum corpore datum, ZiLIOTO, cit n. 11, pp 6 y ss. Al respecto, la autora señala: “Nella prospettiva dell'estensione della tutela aquiliana, ciò che interessa è che Gaio dica che l'actio legis Aquiliae veniva concessa solo contro chi avesse provocado un danno corpore suo”. Y según Pugliese, cit n. 7, p 605: “In un primo momento prevalse un'interpretazione letterale e restrittiva del testo della lex, per cui si esclusero dal suo ámbito di applicazione tutte quelle condotte che non consistessero in un facere positivo e concreto (così si escluse per esempio l'applicabilità dell'actio ex lege Aquilia per dani conseguenti ad un contegno meramente omissivo), e si richiese che il danno avvenisse mediante contatto diretto fra la persona del dannegiante e la cosa e consistesse nella distribuzione o nel deterioramento materiale della cosa stessa (damnum corpore corpori datum)”.

Las razones de estas restricciones en la aplicación de la ley, son señaladas por CHIRONI, La culpa en el Derecho

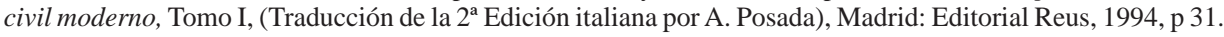
Según él, que el daño debiera ser causado corpore et corpori respondía a las concepciones restringidas nacidas de un análisis imperfecto de las relaciones jurídicas: "Como quiera que los derechos sobre una cosa suponen la facultad de tenerla y sujetarla directamente, ni se puede tomar la noción abstracta del "peso sobre la cosa”, el daño en ella se restringía a los términos del deterioro material, derivado del contacto del cuerpo ofendido con el ofensor".

14 Sobre esta cuestión, Betti, Emilio, Istituzioni di Diritto Romano, Milán: Guiffrè Editore, $4^{\text {a }}$ Edición, 1965 , p 510 y Schrage, Eltjo, "Negligence. A comparative and historical introduction to a legal concept" A.A.V.V. Neglience. The comparative legal history of the Law of Torts, Berlín: Duncker \& Humbolt, 2001, p 24, quien indica: "The requirement of a direct causal relation between the action and the effect is another test wich impedes liability for omissions (...) This requirement of a direct causal relation between the positive act and the harm was mitigated in the course of the time: an actio utilis or and action in factum could be given when the defendant had locked up another person's slave or animal and the latter came to starve, or when a defendant had so excited another person's beast of burden or pack animal, that it collapsed and died". En relación con el tema de las omisiones, aún cuando no precisa la época, ni de que forma, con lo que parece referirse al texto de la ley, Colombo, cit n. 12, p 72: “Algunos autores pretenden que la omisión culpable o dolosa no aparejaba consecuencias, porque, no existiendo vínculo jurídico contractual, nadie estaba obligado a asumir una actitud determinada. Pero la culpa in omittendo caía, sin duda, dentro de la ley Aquilia, aunque en forma indirecta, es decir, cuando el culpable realizaba primero un hecho comprendido en sus preceptos".

Buenos ejemplos en el que una clara conducta omisiva dio lugar a la ampliación del ámbito de la ley, pueden 
Los requisitos de la lex Aquilia, con especial referencia al daño.

Lecturas desde las distintas teorías sobre el capítulo tercero.

señala: "Existiendo la obligación de resarcir por causa de injusto suceso, cualquiera que fuese el modo de aparecer en el hecho, se extendió el alcance de la ley hasta incluir el perjuicio ocasionado a la cosa sin ejercitar sobre ella un acto físico (corpore); o sin que se ofendiese a su materialidad física (corpori); figuras ambas (si non corpore fuerit datum, neque corpus laesum fuerit) que, no estando comprendidas en el texto de la ley, no podían producir a favor del ofendido la acción que directamente procedía de aquélla". ${ }^{15}$

En cuanto a la relación de causalidad, lo primero que debe decirse es que la lex Aquilia no señalaba cuando un evento debía considerarse consecuencia de un cierto comportamiento. La interpretación de los verbos, de otra parte, permitía concluir que la conducta debía ser considerada causa directa del resultado. ${ }^{16}$ También resulta obvio que los juristas romanos no se dedicaron al tratamiento dogmático del tema causal, ni siquiera lo abordaron especialmente, sino que, por el contrario, las cuestiones causales son desarrolladas en el contexto de la interpretación operativa de las palabras contenidas en los capítulos primero y tercero, a los que nos hemos referido.

Si seguimos las ideas que sobre esta materia ha señalado MacCormarck, parece ser que los juristas romanos utilizaron la expresión causa en un sentido ordinario o común y que no aplicaron ninguna concepción filosófica para la decisión de las cuestiones causales. ${ }^{17}$ Lo cierto es que el problema causal se desarrolló junto con las reglas que permitieron a los juristas distinguir entre la acción directa y el otorgamiento de actio in factum. En efecto, dicho desarrollo

encontrarse en el pasaje de Luciano Rufo (D. 42, 1, 34). Según este caso, el impedir llevarle el alimento o el lecho que necesita a un condenado, puede configurar la acción útil. El pasaje reza: "Si victum vel stratum inferri quis iudicato non patiatur, utilis in eum poenalis actio danda ets vel, ut quídam putant, iniuriarum cum eo agi poterit" ("Si alguno no consintiera que se le lleve al condenado la comida o la cama, se ha de dar contra él la acción penal útil, o, según opinan algunos, se podrá ejercitar contra él la acción de injurias". Mayores comentarios sobre el caso, en Valiño, Emilio, Acciones útiles, Pamplona: Ediciones Universidad de Navarra, 1974, p 68; y, en el de Neratio, D. 9, 2, 9, 2: "Si quis hominem fame necaverit, in factum actione teneri Neratius ait" ("Si uno hubiese matado de hambre a un esclavo, dice Neratio que queda obligado por una acción por el hecho"), recogido en el pasaje gayano 3, 219. Maccormack, Geoffrey, "Juristic interpretation of the lex Aquilia" A.A.V.V. Studi in onore di Cesare Sanfilippo, Tomo I, Milán: Giuffrè Editore, 1982, p 273 lo cita dentro del grupo de casos en que la culpa decidía la imputación del resultado a un sujeto cuando la causalidad era mediata. Chironi, cit n. 13, p 31 .

16 Aunque esta cuestión tampoco puede establecerse como regla, pues hubo casos en los que se otorgó una acción directa sin existir un contacto físico inmediato entre el sujeto hecho responsable y el dañado o el objeto dañado, como por ejemplo en la opinión de Próculo en el famoso caso del perro irritado, en D. 9, 2, 11, 5 o en el no menos conocido caso del barbero, a propósito de la opinión de Mela en D. 9, 2, 11pr.

17 Aún cuando no podamos detenernos en esta cuestión, lo cierto es que hay varias teorías que afirman la influencia de la filosofía griega o, mejor dicho, del pensamiento filosófico griego en la jurisprudencia romana, así como otras tantas que la rechazan. Por tratarse de un problema de filosofía del derecho, de momento, por todos, puede citarse el esclarecedor trabajo de Reinoso, Fernando, "La autonomía de la jurisprudencia romana frente al pensamiento filosófico griego" A.A.V.V. Estudios en Homenaje al profesor Juan Iglesias, Tomo II, Madrid: Seminario de Derecho Romano Urcisino Alvarez, 1988, pp 1021-1039. 
parece haber concluido con la formulación de la conocida regla de Celso, quien distingue entre occidere y mortis causam praestare. Según MacCormack, en el desarrollo de dicha regla, especialmente al referirse a la causa, los juristas romanos no indicaban necesariamente una vinculación lógica entre una conducta y un resultado, sino más bien lo que según la experiencia era probable que sucediera. Así -como ocurre con la jurisprudencia moderna, según nos parece a nosotros- las cuestiones causales se soslayaron cuando la causa era directa, evidente, inmediata. $\mathrm{Si}$, por el contrario, el vínculo era indirecto, los juristas prestaron atención al problema causal, aplicando, repetimos, criterios empíricos. ${ }^{18}$

En cuanto a la iniuria y la culpa, tradicionalmente se opina que la primera, a diferencia del delito de iniuria, representaba un acto contrario a Derecho (o sine iure, según las posiciones) y que la culpa correspondió a un desarrollo posterior, por la vía pretoria. Este esquema tan simple es en verdad bastante más complejo de lo que parece. No está para nada claro el concepto de iniuria. Desde luego la comprensión del capítulo tercero influye sobre esta cuestión, pues la tesis de Daube o más bien los seguidores de ésta, ven una equivalencia plena entre los delitos de iniuria de las XII Tablas y el elemento del delito de damnum. ${ }^{19}$ La visión contraria viene desde las tesis contrarias. Así, por ejemplo Jolowicz considera que los verbos del capítulo tercero no se avienen con las lesiones personales, sino que se refieren más bien a la destrucción completa de la cosa. ${ }^{20}$ La iniuria entendida como acto contrario a Derecho presenta iguales o

18 MarCormack, Juristic interpretation..., cit n. 14, pp 265-270. En otros trabajos suyos ha repetido esta misma idea, como por ejemplo en MacComarck, Geoffrey, “Aquilian Studies”, SDHI, No 41, 1975, p 12, gráficamente señala: "Still less can it be assumed that those jurist who wrote commentaries on the lex Aquilia devoted sections to the treatment of causal questions (...) The jurist is asked to determine whether the facts of a particular case constitute occidere, or urere, frangere or rumpere". En MacCormack, Geoffrey, "Fault and causation in early Roman law: an antropological perspective", RIDA, $\mathrm{N}^{\mathrm{o}} 28, \mathrm{p} 124$. Aunque el trabajo transcurre por otros derroteros y hace una breve referencia sobre la cuestión, refiriéndose a los primeros siglos del desarrollo del Derecho romano y sólo circunscribiendo su análisis a la Ley de las XII Tablas, la lex Numae y la lex Aquilia, sostiene que el material parece sugerir que no parece haberse desarrollado en los primeros siglos una doctrina o teoría de la casualidad para la solución de los problemas jurídicos que se les presentaron, sino que, por el contrario, se discutieron las cuestiones de causalidad en términos muy concretos.

Desde luego, la mayoría de la doctrina que ha tratado el problema causal, entiende que el problema de la misma forma. Sobre esta cuestión puede consultarse a Valditara; Damnum iniuria..., cit n. 7, pp 853 y 854 . Para Zimmermann, cit n. 1, p 988 y 991: "The analysis of delict in terms of objective and subjective requirements, of factual and normative elements and, more generally, of abstract conceptual thinking, is thoroughly un-Roman. The issue of causation provides a good example". Más adelante agrega: "There is no evidence for the use by the jurists of a specific theory of causation".

19 Muy claro sobre este punto y por todos, Watson, The law of obligations..., cit n. 6, pp 81-83, considerando precisamente que tal equivalencia es la principal prueba de la tesis de Daube en Watson, Alan, "Personal injuries in the XII Tables", IURA, N ${ }^{\circ} 17,1966$, pp 260 y ss, aunque las ideas de la iniuria como acto de violencia vienen desde otras voces. Véase, sobre este tema, Kelly, The meaning..., cit n. 7, pp 81-83 y especialmente La Rosa, Franca, "Il valore originario di "iniuria" nella "lex Aquilia", $L A B E O, \mathrm{~N}^{\circ} 44,1998$, pp 368 y ss.

20 Jolowicz, cit n. 6, pp 221-222, aunque estima que hay dos excepciones. Una la constituye la evolución de rumpere hacia corrumpere. La segunda es que en ocasiones se hacía referencia a los esclavos quemados, aunque se utilizara solamente el verbo adurere y no urere. En términos similares se pronuncia MacCormack, On the third..., cit n. 5, p 171. 
Los requisitos de la lex Aquilia, con especial referencia al daño.

Lecturas desde las distintas teorías sobre el capítulo tercero.

mayores problemas. No está claro si tenía un valor puramente objetivo ${ }^{21}$ o si contemplaba el dolo. ${ }^{22}$ En ambos supuestos los autores se dividen a la hora de determinar cuando la interpretación dio paso a la culpa estricta. ${ }^{23}$

Un breve repaso de la iniuria nos muestra que la cuestión tratándose de la culpa no es menos difícil. Tanto en el ámbito aquiliano como en el de la custodia, ha habido un verdadero movimiento de vaivén, desde posiciones subjetivistas hacia las objetivistas, para volver luego a las subjetivistas, con una clara superación del problema en la última mitad del siglo XX derivada del esfuerzo de varios autores.

En efecto, puede visualizarse una primera corriente que identifica la culpa o bien con la mera imputabilidad -como Rotondi- o bien como Arangio Ruiz, quien piensa en la culpa como equivalente al nexo de causalidad durante la época republicana y clásica, adjudicando a los juristas justinianeos el desarrollo de la culpa como negligencia. De esta forma, la definición de Mucio, en D. 9, 2, 31 pr sólo tendría por objeto establecer un mínimo psíquico para reconocer la consecuencia dañosa o bien se trataría de un pasaje derechamente interpolado.

21 Desde luego estas ideas vienen desde las tesis "objetivistas", desarrolladas al amparo del método interpolacionístico. Por todos, Arango Ruiz, Vincenzo, Responsabilità conttratuale in Diritto romano, Napolés: Editricce Eugenio Jovene, Reimpresión 2 ${ }^{\text {a }}$ Edición, 1957, p 227, para quien la iniuria fue utilizada para excluir la aplicación de la pena cuando se había actuado conforme a Derecho. Una mayoría se pronuncia en este sentido, aunque no se correspondan con las ideas de Arangio. Por ejemplo, Perrin, Bernard, "Le caractère subjectif de l'iniuria aquiliene à l'époque classique" A.A.V.V. Studi in onore di Pietro de Francisci, Volumen Cuarto, Milán: Guiffrè Editore, 1956, p 265, quien explica que las XII Tablas desarrolló dos modelos: uno basado en el dolo del autor y el otro en la iniuria, como sinónimo de no conformarse con el ordenamiento jurídico. Un autor que se encuentra en las antípodas del pensamiento de Arangio en relación con la culpa, opina en similar sentido a propósito de la iniuria. Ese autor es Schipani, Sandro, Responsabilità “Ex lege Aquilia”. Criteri di imputazione e problema della "culpa”, Turín: Giappichelli Editore, 1969, p 43.

22 El más claro defensor de la tesis es Burdese, Alberto, Manuale di Diritto Privato Romano, Turín: Utet, $4^{\text {a }}$ Edición, 1993, p 53, pero opiniones semejantes se encuentran en Cannata, Carlo Augusto, Per lo studio della responsabilità per colpa nel diritto romano classico, Milán: La Giolardica, 1969, p 305 y Van Warmelo, cit n. 6, pp 344 y ss, quien estima que los capítulos de la lex contemplaban actuaciones dolosas en la esfera de terceros.

23 Se trata de un problema sumamente complejo e imposible de abordar en estas breves páginas, pero básicamente pueden advertirse dos tesis. Para un sector, la culpa puede atribuirse a los tardos republicanos o bien a los juristas clásicos. La primera tesis la defiende, por ejemplo, Perrin, cit n. 21, p 268-270, mientras que la segunda a D’Ors, cit n. 8, p 436. Estos autores parten del supuesto que los pasajes clásicos, especialmente los dedicados a la culpa, como el famoso texto de Quinto Mucio, del D. 9, 2, 31pr son originaros o al menos han conservado en esencia las opiniones de los juristas republicanos y clásicos. Véase, por ejemplo, los esfuerzos reconstructivos de Schipani, Responsabilità "Ex lege Aquilia"..., cit n. 21, pp 141 y ss tratándose del caso del D. 9, 2, 31 pr para afirmar su originalidad. La segunda corriente vino de la mano de los interpolacionistas, quienes defendieron que la culpa fue fruto del desarrollo del Bajo Imperio, siendo entendida como mero vínculo causal aún durante el período clásico. Desde luego, la expresión culpa se considera interpolada cada vez que ésta aparece en las decisiones de casos a propósito de la lex Aquilia. Por todos, Arangio Ruiz, Responsabilità..., cit n. 21, especialmente pp 225 y ss, pero destacan otro importantes autores como Guarino, Antonio, Diritto Privato Romano, Napolés: Editore Jovene Napoli, 1997, pp 1024-1025. 
Además, Rotondi utiliza como argumento sustantivo el principio corpore corpori, para afirmar desde él que la ley sólo contempló las conductas comisivas, de acuerdo con el texto D. $7,1,13,2$ y que la omisión (por tanto, la negligencia), fue un producto del desarrollo justinianeo. Este aspecto del planteamiento de Rotondi nos parece especialmente criticable, pues dejando aparte la cuestión de si el principio corpore corpori formaba parte del contenido originario de la ley -como en las posiciones tan dispares de Pugsley y Daube, como veremos a propósito del daño-, la negligencia no puede ser confundida con las formas de manifestación de la voluntad, comisiva u omisiva, tal como han reconocido romanistas modernos. ${ }^{24}$

Con todo, la tesis objetivista más extrema pertenece sin duda alguna a Arangio Ruiz, el cual reduce el contenido de la culpa, durante los períodos republicano y clásico al vínculo causal. Tratándose de la lex Aquilia sus principales argumentos pueden deducirse a dos: primero, al igual que Rotondi considera que el principio corpore corpori demuestra que la culpa no pudo ser admitida en época temprana. En segundo lugar, al enfrentarse a los pasajes de la lex Aquilia, pero especialmente el texto del D. 9, 2,31pr, estima que la referencia a la culpa está interpolada, pues el desarrollo de la negligencia sería fruto de la época justinianea. ${ }^{25}$

La segunda gran corriente, en la antípoda de la tesis objetiva, considera que la culpa aquiliana equivalía a la negligencia. En esta opinión la culpa constituía un criterio de responsabilidad, consistente en la desviación del estándar del buen padre de familia. Desde luego, en este orden de pensamiento, la culpa tuvo partida de nacimiento en la definición de Mucio, del ya citado D. 9, 2, 31pr y no se considera ningún texto interpolado. ${ }^{26}$

Finalmente, tal como ocurre en el terreno de la custodia o contractual, un grupo de autores, partiendo de serias críticas a lo métodos anteriores, buscan alternativas para el problema de la culpa en el Derecho romano, siendo dignas de destacar, aunque brevemente, las contribuciones de MacCormack, Schipani y Martínez Sarrión. ${ }^{27}$

Rotondi, Giovanni, "Dalla lex Aquilia all art. 1151 del Cod. Civ. Ricerche storico dogmatiche", Rivista di Diritto Commerciale, $\mathrm{N}^{\circ} 14,1916$, pp 953-957. Entre los romanistas que critican la confusión negligenciaomisión, puede consultarse a Voci, Pasquale, "Diligentia", "Custodia”, "Culpa”. I dati fundamentali”, SDHI, N 56, 1990, p 47 y Buckland, W.W., The main institutions of Roman private law, Londrés: Cambridge University Press, 1931, p 333.

25 Arangio, Reponsabilità..., cit n. 21, pp 221 y ss. Cabe advertir que hay algunos autores que consideran la tesis superada. Véase especialmente y por todos a Ankum, Hans, "La responsabilità conttratuale nel Diritto romano classico en el Diritto Giustinianeo" A.A.V.V. Diritto romano e Terzo Millennio. Raici e prospettive dell'esperienza giuridica contemporanea, Napolés: Edizioni Scientifiche Italiane, 2004, p 144.

26 Referentes de esta posición son Voci, "Diligentia"..., cit n. 24, pp 33 y ss y Visky, Károly, "La responsabilité dans le droit Romain à la fin de la Republique" A.A.V.V. Mélanges Fernand De Visscher, Tomo II, RIDA, Brúselas, 1949, pp 448 y ss.

27 Uno de los esfuerzos más importantes por desnudar los problemas de métodos que importan la aplicación de las categorías responsabilidad objetiva-subjetiva se encuentran en Robaye, René, "Responsabilité objective ou subjective en droit Romain", TR, N 18, 1990. 
Los requisitos de la lex Aquilia, con especial referencia al daño.

Lecturas desde las distintas teorías sobre el capítulo tercero.

En cuanto a MacCormack, todo su estudio se fundamenta en una revisión crítica de la utilización de la nomenclatura responsabilidad objetiva-subjetiva y de la consideración de la culpa como criterio de responsabilidad. En el pensamiento de MacCormack, ni los juristas clásicos resolvieron puramente casos concretos, ni los juristas de la época justinianea amaban los conceptos abstractos. De esta manera, dado que la culpa era concebida desde la perspectiva del contenido de una obligación y no como criterio de responsabilidad, el autor propone que fue desarrollada desde el período republicano, pero entendiéndola como un conducta sujeta a reproche individual, es decir, un comportamiento reprochable, que a diferencia de la negligencia, no atendía a un modelo o patrón abstracto de conducta, representado por el buen padre de familia. La culpa como falta, tal como el autor la define, es el quebrantamiento de una regla que prescribe formas de comportamiento o la conducta misma prohibida por las reglas, de modo que la culpa en su concepto se nos presenta con un sentido muy amplio y funcional. ${ }^{28}$

Aunque con una metodología diferente, Schipani se acercará a las conclusiones del autor inglés. Con particular claridad, diferencia dos grandes grupos de concepto de la culpa-escapando de la tradicional dicotomía culpa subjetiva-objetiva-. Según el primero, la culpa se encuentra objetivada, en el sentido que se define como trasgresión a una norma. La segunda perspectiva no atiende a la circunstancia externa, sino al comportamiento mismo, en la posición del autor frente al hecho. Alejándose de estas perspectivas e intentando una vuelta a los orígenes del instituto, prefiere definirlo como un comportamiento que en sí mismo es objeto de juicio desfavorable, cuando es una conducta humana la que se valora. Si se trata de una cosa inanimada o de un animal, suele emplearse la expresión culpa como sinónimo de causalidad.

A nuestro juicio, hay claros puntos de contacto ente las tesis de MacCormack y Schipani (así como en la custodia habían encuentros entre el primero y Cannata), pero más allá de las diferencias, el principal punto de acuerdo radica en que ambos autores exploraron caminos de superación de la dicotomía tradicional, proponiendo un concepto más amplio y funcional de la culpa, la que se aparta del modelo de la negligencia, aún cuando cabe anotar diferencias metodológicas.

En este sentido, Schipani hace una reconstrucción histórica de los textos y aún cuando no desarrolla una reconstrucción dogmática, ni elabora conclusiones generales, del estudio de su pensamiento puede deducirse claramente que la culpa estuvo presente desde los republicanos,

28 El pensamiento del autor resulta de un estudio conjunto de algunos de sus trabajos, entre los que puede consultarse MacCormack, Geoffrey, "Dolus", "Culpa" and "Diligentia". "Criteria of liability or content of obligations", Index, № 22, 1994, pp 189 y ss; MacCormack, Geoffrey, "Juristic use of the term dolos: Contract", ZSS, № 22, 1984, pp 520 y ss, para la diferenciación culpa-criterio de responsabilidad y culpa-contenido de la obligación. Para el concepto de la culpa como falta y no como negligencia, MacCormack, Geoffrey, "Aquilian culpa" A.A.V.V. Essays in legal history for David Daube, Edimburgo: Scottisch Academia Press, 1974, p 202 y, MacCormack, Geoffrey, "Culpa", SDHI, No 38, 1972, pp 124-134. 
pero que ésta fue evolucionando desde el casuismo de éstos, hasta la colocación de la negligencia como centro del sistema por los bizantinos, refutando categóricamente de paso la tesis objetivista. MacCormack, en cambio, se desenvuelve en consideraciones dogmáticas y arranca de la premisa -muchas veces implícita- que todos los textos son genuinos. ${ }^{29}$

\section{Especial referencia al daño}

\section{A. Plan}

Finalmente, en cuanto al daño, como se sabe, la evolución de la lex Aquilia vino de la mano de la interpretación de los verbos, occidere -para el capítulo primero-; urere, frangere, rumpere en el caso del tercero. Dicha interpretación influyó especialmente en la evolución de la causalidad e indirectamente en la culpabilidad, en la medida que éste constituyó la herramienta normativa que decidía varias de las cuestiones causales. Parecería, por cierto, que un análisis detenido del desarrollo de dichos verbos podría mostrarnos todo lo que tenemos que saber del daño; sin embargo, este punto de vista no parece del todo correcto.

A nuestro juicio hay dos cuestiones relativas al daño respecto de las que vale la pena detenerse: uno es repasar, aunque muy brevemente, lo que ha dicho la doctrina sobre el concepto de este elemento, desde donde pueden advertirse dos lecturas diferenciadas, estrechamente ligadas a la interpretación que se hace del carácter originario de los capítulos primero y tercero.

En segundo lugar, podríamos desarrollar con un poco más de detención la reparación de los intereses de la víctima a la luz de la lex Aquilia. Como explica Voci, hay dos aproximaciones en lo que se refiere al resarcimiento del daño, entendido éste como la reconstitución del patrimonio del dañado. Un primer criterio, más estrecho, concibe el daño entre los efectos inmediatos del ilícito. En este caso se habla de criterio objetivo de valoración, en cuanto se

Schipani, Responsabilità "Ex lege Aquilia"..., cit n. 21, pp 93 y ss. En trabajos posteriores ha repetido o profundizado estas ideas. Por ejemplo, en Schipani, Sandro, "Análisis de la culpa en Justiniano 4,3" A.A.V.V. Responsabilidad por daños en el Tercer Milenio. Homenaje al profesor doctor Atilio Aníbal Alterini. Buenos Aires: Abeledo Perrot, 1997, pp 127 y ss. El autor hace una comparación entre las Institutas de Justiniano con las Instituciones de Gayo o algunos casos de juristas clásicos recogidos en el Digesto. En principio, reitera la idea que la culpa no es sólo negligencia, sino que incluye la idea de negligencia en el sentido de conducta voluntaria censurable, que en cuanto tal constituye un adecuado fundamento por la imposición del castigo. Más adelante agrega: "Pero si queremos escoger en modo unitario el significado de la culpa, incluyendo todas las facetas vistas, debemos entender que ella se refiere a una conducta voluntaria prohibida sea por lo más de normas de prudencia, pericia, diligencia, sea también, más genéricamente, por otras disposiciones, cuya violación muestra la conducta reprochable”. También, sobre la comparación de casos, como el de lanzamiento de jabalinas en J, 4, 3, 4 en comparación con D. 9, 2, 9, 4 reitera que en la época justinianea se produce una sistematización de la culpa como elemento central del sistema resarcitorio, exigiéndose como elemento autónomo para afirmar la responsabilidad, con independencia de la actuación sine iure. 
Los requisitos de la lex Aquilia, con especial referencia al daño.

Lecturas desde las distintas teorías sobre el capítulo tercero.

propone la estimación de la cosa, la aestimatio rei. De otra parte, se considera la relación entre la conducta dañosa y la situación compleja creada en el patrimonio de la víctima. Se aplica así un criterio subjetivo, del id quod interest. ${ }^{30}$ En las páginas siguientes veremos las distintas aproximaciones de los autores para el desarrollo desde el criterio de la aestimatio rei hasta el principio del id quod interest, que van de la mano, nos parece a nosotros, del primigenio concepto del damno corpore corpori al desarrollo posterior de la ley por la vía de las acciones decretales. ${ }^{31}$

\section{B. Concepto del daño}

Como explica Kelly, la expresión damna es un arcaico genitivo singular de la palabra femenina damna; así la frase damna esto/sunto podría ser una fósil primo de pater/filus familias. Este autor y Daube señalan que la expresión deriva de la raíz damenon, que significa "dar". ${ }^{32}$ En cualquier caso, luego de su evolución, como afirma Fernández, la voz damnum pasó a significar el perjuicio que se sufre en el patrimonio o en los bienes, o en el honor, fama y consideración. ${ }^{33}$

Ahora bien, el damnum sancionado en los capítulos primero y tercero de la ley, correspondían a un término técnico y preciso, propio de ella, traducido en los verbos occidere -para el primero- y urere, frangere, rumpere, para el tercero. Para ello es preciso distinguir entre damnum facere/damnum dare. Una explicación de las diferencias jurídicas entre los binomios damnum dare/damnum facere se encuentra en Castresana, para concluir que: "La realización de determinada conducta por parte de un sujeto capaz -“damnum facere”-, que coloca a otro en una situación de gasto o pérdida patrimonial - “damnum dare”-, pasa en la Lex Aquilia por la tipificación de ciertos eventos dañosos como acciones materiales de damnum. Occidere, pecuniam acceptam, urere, frangere, rumpere, son todas las posibles, y a su vez

30 Voci, Pasquale, Istituzioni di Driritto Romano, Milán: Giuffrè Editore, $3^{\text {a }}$ Edición, 1954, pp 412-414. En el mismo sentido, antes en Voci, Pasquale, "L'estensione dell'obbligo di risarcire il danno nell diritto romano classico" A.A.V.V. Scritti in onore di Contardo Ferrini pubblicati in occasione della sua beatificazione, Volumen Segundo, Milán: Sociedad Editriche Vita e pensiero, 1934, pp 377-383, en el que explica el desarrollo del principio id quod interest como un mecanismo del ius honorarium destinado a extender el resarcimiento de los perjuicios.

31 Como explica Zimmermann, cit n. 1, pp 970-972, a propósito del carácter mixto de la ley, en lo que respecta al primer capítulo la valoración inicialmente referida al corpus, con el curso del tiempo fueron siendo incluidos otros ítems, de acuerdo a los requerimientos del caso individual, hasta llegar a la valoración del interés de la víctima. Agrega que una cuestión similar ocurrió con el capítulo tercero, en el cual también operó un desarrollo desde una evaluación estándar, relativa a la disminución del valor del objeto hasta una más refinada e individual evaluación de los perjuicios del demandante. Según el autor, dicha valoración llegó a comprender lo que los juristas del ius commune conocieron como daño emergente versus lucro cesante.

32 Kelly, The meaning..., cit n. 7, p 73 y Daube, David, "On the use of the term damnum" A.A.V.V. Studi in onore di Siro Solazzi, Napolés: Casa Editriche Eugenio Jovene, 1948 pp 93 y ss.

33 Fernández Prieto, Marta, La difamación en el Derecho romano, Valencia: Tirant Lo Blanch, 2002, pp 153-154. 
únicas, formas tipificadas en el plebiscito aquiliano como supuestos de "damnum facere"; otros eventos dañosos que no sean exactamente éstos, no entran dentro del tipo normativo sancionado por la Ley Aquilia. La realización de aquellas conductas, previstas en la norma como comportamiento de "damnum facere", conduce al resultado "damnum dare". ${ }^{4}$

Que el término técnico preciso para el delito de damnum es el de damnum facere y no dare, había sido puesto de manifiesto por Cannata, quien señala que: "Altra cosa notevole è nel fatto chen damnum è retto dal verbo facere, e non da dare, como invece la giurisprudenza costruì, traendola proprio de questo testo, l'espressione sintetica per indicare il danno aquiliano: damnum iniuria datum. La norma del terzo capo della lex Aquilia è dunque incentrata sulla locuzione: damnum facere alicui alicuis rei”, aún cuando luego advierte que el daño aquiliano aparece en las fuentes regularmente como damnum dare y no damnum facere, pero indica que en ningún caso en lengua latina ambos términos eran sinónimos, sino que, por el contrario, tenían un significado contrapuesto. Para el autor, damnum facere equivalía a damnum pati, que significaba un daño acarreado a alguien, que se obtiene del dativo alteri. ${ }^{35}$

Una visión un tanto distinta nos ofrece Daube, quien hace un análisis detallado de término damnum en las fuentes romanas, tanto en la literatura como en las leyes, para concluir que éste significaba pérdida o gastos en los que incurría el propietario. Un análisis le permite concluir que el damnum, técnicamente considerado, no se refería al perjuicio inferido sobre el objeto, sino más bien a las pérdidas infligidas al propietario. En suma, el término damnum jamás fue ocupado para referirse ni a las acciones materiales de la ley, ni al deterioro o destrucción de las cosas. ${ }^{36}$

34 Castresana, cit n. 9, pp 18 y ss. En un sentido similar, Watson, Roman Private law..., cit n. 6, p 151, nota 6, señala que damnum facere significa literalmente "hacer una pérdida", mientras que damnum dare implica "infligir una pérdida", agregando que ambos términos no pueden ser confundidos, permaneciendo en la lex Aquilia su significado diferenciado. En sentido similar, Maccormack, On the third..., cit n. 5, pp 176-178. Se trata, en verdad de una opinión generalizada. Una posición distinta ofrece Kelly, The meaning..., cit n. 7, pp 78 y ss, quien contrariamente estima que la expresión damnum faxit, del D. 9, 2, 27, 5 permite concluir que en las fuentes latinas, especialmente en Plauto, la frase significaba la pérdida sufrida, mientras que damnum dare pudiese haber significado "infligir una pérdida", pero que no resulta inconcebible que durante el año 286 a.C. damnum faxit pudiese haber significado "infligir una pérdida, quedando fijado para damnum dare el sentido contrario. Tal como lo explican estos autores, es lo que se ha desarrollado en los sistemas contemporáneos como daño evento, versus daño resultado, según se atienda al comportamiento dañoso o al resultado lesivo en sí mismo. Se refieren a esta materia, con bastante detalle Alpa, Guido. Bessone, M., Atipicità dell'illecito, Parte Primera. Il profilli dottrinali, Milán: Guifrrè Editore, 1977.

35 Cannata, Il terzo capo..., cit n. 1, p 114. Interesantes comentarios sobre la ampliación del daño en época clásica y especialmente justinianea puede encontrarse en Volterra, Eduardo, Instituciones de Derecho Privado Romano, Madrid: Civitas, Reimpresión $1^{\text {a }}$ Edición, 1988, pp 562-563.

36 Daube, David, On the use..., cit n. 32, pp 93-139. Aunque no comparte sus ideas, Van Warmelo, cit n. 6, p 338, está de acuerdo en que el término damnum significaba pérdida, dispensa innecesaria y, en definitiva un menoscabo para otro sujeto. Desde luego, no tiene sentido repetir los textos que el autor ha citado de manera absolutamente detallada, pero nos parece que bastará con referirse dos de dichos textos, que a nuestro juicio reflejan muy 
Los requisitos de la lex Aquilia, con especial referencia al daño.

Lecturas desde las distintas teorías sobre el capítulo tercero.

\section{El problema del principio id quod interest}

Ahora bien, en la visión de Daube, la distinción que apuntamos en párrafos anteriores tiene importancia para las sanciones y para la valoración de las pérdidas. Como hemos analizado, Daube estima que el tenor originario de la ley separaba los capítulos primero y tercero. Mientras el primero se refería a la muerte del esclavo o del ganado, en el tercero se trataba originariamente de las heridas a seres animados, de ahí que la sanción fuera fijada hacia el futuro y la valoración consistiera en la estimación de la pérdida para el propietario.

Aquí se encuentra el punto en cuestión, pues dado que el capítulo primero sólo contenía una hipótesis concreta, estableciendo una sanción fija, el término damnum sólo fue ocupado en el capítulo tercero -para referirse al primero, los autores sólo habrían ocupado la expresión occidere- ${ }^{37}$ Así, dicho capítulo contendría el principio del id quod interest, pues habría permitido la valoración de los menoscabos, pérdidas y gastos efectivamente sufridos por el propietario, con independencia de la afectación material del bien -animado- de su propiedad.

De hecho el autor afirma que: "There exists an intimate connection between damnum and the principle of interesse”; de manera que el capítulo tercero tomaría el concepto del damnum al no haber un hecho concreto y específico al cual circunscribir la conducta, abandonando la pena fija, para establecer un sistema de evaluación de las pérdidas que el propietario experimentó como consecuencia de las heridas inferidas a bienes de su dominio. Por el contrario, el capítulo

claramente las ideas que el autor ha querido expresar. Uno es el pasaje de Papiano, en D. 3, 6, 9: "De servo qui accusatur, si postuletur, quaestio habetur: quo absoluto in duplum pretium accusator domino damnatur: sed et citra pretii aestimationem quaeritur de calumnia eius. separatum est etenim calumniae crimen a damno quod in servo propter quaestionem domino datum est" ("Cuando se solicita que un esclavo acusado sea sometido a tormento, si viene a ser absuelto, se condena al acusador, a favor del dueño, por el doble del precio del esclavo, pero, además de la estimación del precio, se le hace responsable de la vejación, pues este delito es independiente del daño que se causó al dueño en la persona del esclavo sometido a tormento"). Este texto es muy similar al del Ulpinao, en D. 9, 2, 27, 17: "Rupisse eum utique accipiemus, qui vulneraverit, vel virgis vel loris vel pugnis cecidit, vel telo vel quo alio, ut scinderet alicui corpus, vel tumorem fecerit, sed ita demum, si damnum iniuria datum est: ceterum si nullo servum pretio viliorem deterioremve fecerit, Aquilia cessat iniuriarumque erit agendum dumtaxat: Aquilia enim eas ruptiones, quae damna dant, persequitur. ergo etsi pretio quidem non sit deterior servus factus, verum sumptus in salutem eius et sanitatem facti sunt, in haec mihi videri damnum datum: atque ideoque lege Aquilia agi posse” ( “...Si no hubiese devaluado o hecho más inútil al esclavo, cesa la Aquilia y sólo habrá de demandarse por injurias, porque la Aquilia persigue aquellos quebrantamientos que causan daño. Por consiguiente, aunque el esclavo no haya sido devaluado, pero se hicieran gastos en su curación y salud, en esto me parece que se causó daño y, en consecuencia, puede demandarse por la ley Aquilia”).

37 Contrario a esta precisa posición es Pugsley, David, "Damni injuria", $T R, N^{\circ} 36,1968$, pp 377, quien discutiendo las ideas de Kelly, que como hemos visto considera que la expresión damnum faxit del capítulo tercero pudo haber reemplazado a iniuria faxit, pasando a ocupar esta última el lugar posterior a los verbos, como ablativo adverbial, estima que la palabra fue lo suficientemente fuerte como para no creer que estuvo presente en el texto, incluyendo el capítulo primero. Cita, como ejemplo, el pasaje del D. 9, 2, 33pr: in lege enim Aquilia damnum consequimur. 
primero no se habría referido al principio del interés, por las razones antes señaladas, de ahí el carácter fijo de la sanción; sin embargo, el autor reconoce que posteriormente dicho "principio" fue trasladado al ámbito del capítulo primero, el que no parece haber sido adoptado hasta Neracio. ${ }^{38}$ En efecto, el interés es considerado a propósito del capítulo primero, como señala el autor, en los pasajes de Ulpiano, en D. 9, 2, 23pr y 9, 2, 21, 2, así como en el Paulo D. $9,2,22,1 .^{39}$

Una cuestión interesantísima que se deriva de la tesis de Daube, desde una comprensión del carácter originario de la ley como fundamentalmente resarcitorio, es la negación del principio corpore corpori. En efecto, según el autor, tanto Gayo como Justiniano, después del primero, declararon que la lex era disponible si quis corpore suo damnum dederit, que es bien distinto a sostener que en la ley se exigiera un damnum dare corpori. De esta manera: “...damnum corpori datum and, of course, damnum corpore corpori datum cannot be reconciled with the Roman usage”. La expresión habría sido resultado de una introducción de los juristas medievales, desde que el daño no era utilizado para la destrucción o deterioro de las cosas, sino que para las pérdidas sufridas para el propietario..$^{40}$

Desde luego, una visión completamente distinta ofrece Valditara en lo que se refiere a la

38 En este caso coincide con Valditara, Giuseppe, Superamento dell'aestimatio rei nella valutazione del danno aquiliano ed estensione della tutela ai non domini, Milán: Giuffrè Editore, 1992, p 16, quien indica que probablemente fue Neracio el primero en proponer, en D. 9, 2, 23pr una solución que comprendiera la liquidación del interés en el caso del esclavo heredero.

39 Daube, On the use..., cit n. 32, pp 139 y ss. Según el pasaje D. 9, 2, 21, 2: "Sed utrum corpus eius solum aestimatus, quanti fuerit cum occideretur, an potius quanta interfuit nostra non esse occsum? Et hoc iure utimur, ut eius quod interest fiat aestimatio” ("Pero ¿valoramos solamente su cuerpo en el valor que tuvo cuando fue muerto o más bien la cuantía de nuestro interés en que no hubiese sido muerto? Y seguimos la regla de estimar el interés"). En cuanto al D. 9, 2, 22, 1: "Item causae corpori cohaerentes aestimantur, si quis ex comoedis aut symphoniacis aut gemellis aut cuadriga aut ex pari mularum unum vel unam occiderit: non solum enim perempti corporis aestimatio facienda est, sed et eius ratio haberi debet, quo cetera corpora depretiata sunt" ("Se estiman también los valores coherentes a la víctima como por ejemplo si se hubiese matado a uno o una de los esclavos comediantes, músicos o gemelos, o a un animal de una cuadriga o de un par de mulas. Porque la estimación no sólo se ha de hacer del cuerpo destruido sino que también ha de tenerse en cuenta aquello en que se han depreciado los otros objetos").

$40 \quad$ Daube, On the use..., cit n. 32, pp 98 y ss. Pugsley, On the lex..., cit n. 7, pp 3 y ss llega a una conclusión similar, pero desde una aproximación diferente, pues según el autor los juristas clásicos adoptaron dos modelos distintos: uno de Gayo, que fijó la distinción en el principio corpore corpori, que según el autor no se encontraba originalmente en los textos, de modo que la acción in factum se otorgó sólo en casos de causalidad mediata, método, que salvo por Juliano, no fue aceptado por otros. Así, el segundo modelo, perteneciente a Celso y otros juristas clásicos, se fundó en el criterio de distinción entre occidere y causam mortis praestare. Ambos grupos coincidieron en algunas oportunidades, pero en otros casos se separaron. En cambio, los juristas republicanos, comenzando por Quinto Mucio, introdujeron la culpa o negligencia para desarrollar las acciones decretales y la intencionalidad o conducta dolosa permitía el otorgamiento de la acción directa. 
Los requisitos de la lex Aquilia, con especial referencia al daño.

Lecturas desde las distintas teorías sobre el capítulo tercero.

valoración del interés. ${ }^{41}$ Ya hemos visto como este autor no comparte la idea de Daube en relación con la sanción del capítulo tercero, pues por el contrario estima que tercero estaba referida hacia el pasado y que la utilización del verbo erit habría sido sólo un error de trascripción. Partiendo de este supuesto, Valditara estima que los regímenes sancionatorios de ambos capítulos eran idénticos y que en cuanto a la estimación del interés del dañado, originariamente se referían al valor de mercado de la cosa, lo que debía conducir a la liquidación de dicho valor del bien destruido o deteriorado. De este modo, durante el siglo II d.C., el capítulo primero llegó a entenderse como un modelo al cual adecuar el capítulo tercero, lográndose una única interpretación de las sanciones para ambos. En todo caso, coincide con Daube, aunque desde premisas distintas, en que la interpretación del capítulo primero fue ampliada para incorporar el principio del interés y cita el mismo pasaje de Ulpiano en D. 9, 2, 21, 2 como una prueba de ello. $^{42}$

No obstante, un par de comentarios pueden efectuar, sobre algunos de los textos analizados profundamente por el autor. ${ }^{43}$ Comienza por el pasaje atribuido a Neracio en D. 9, 2, 23pr. ${ }^{44}$ Según el autor, como hemos visto, Neracio es el primer jurista que parece proponer la extensión del cálculo de la hereditas servi dentro de la estimación del daño, agregando que esta solución no contenía todavía ninguna alusión al principio del id quod interest, enunciado de manera general en D. 9, 2, 21, 2. Luego, se refiere al polémico y conocido pasaje del D. 9, 2, 51, 2.45 Según el autor, este texto, de Juliano, acoge la misma solución Neracio.

Valditara, Superamento dell'aestimatio..., cit n. 38, pp 7 y ss. De hecho el autor indica que le parece poco verosímil la tesis de Daube, en el sentido que la presencia del verbo erit habría sido funcional a la liquidación del interés. En este sentido, estima que esta tesis es desmentida por el pasaje atribuido a Labeón, del D. 9, 2, 27, 35: "Item si tectori locaveris laccum vino plenum curandum et ille eum pertudit, ut vinum sit effusum, Labeo scribit in factum agendum" ("Asimismo, si hubieses alquilado un albañil para que arreglase una cisterna llena de vino y él la hubiese perforado de modo que el vino se derramase, escribe Labeón que ha de demandarse con la acción por el hecho"). Luego, según el autor, si la tesis de Daube fuera cierta, el jurista no habría tenido la necesidad de otorgar una actio in factum, pues la lex Aquilia había contenido la liquidación del valor correspondiente al perjuicio económico causado por el ilícito.

42 Cabe hacer presente que el Valditara, Superamento dell'aestimatio..., cit n. 38, pp 15-176 hace un análisis detallado de las siguientes pasajes D. 9, 2, 7pr; 9, 2, 12; 9, 2, 21, 2; 9, 2, 22pr; 9, 2, 22, 1; 9, 2, 23pr; 1, 2, 3, 4, 5, 6; 9, 2, 27, 17; 9, 2, 29, 3; 9, 2, 30, 1; 9, 2, 33pr; 9, 2, 37, 1; 9, 2, 41 pr; 9, 2, 51, 2; 9, 2, 55; 47, 2, 32; Gayo 3, 212, para demostrar la evolución de la sanción hasta llegar a comprender el interés del dañado. Un excelente resumen del análisis de dichos casos se encuentra en la recensión de Cannata, Carlo Augusto, "In tema di “aestimatio rei" nell'azione aquiliana", SDHI, N ${ }^{\circ}$ 58, 1992, pp 387-396. Otras dos recensiones de esta obra se encuentran en Albanese, Bernardo, "Recensione critiche a Valditara, Superacento dell' aestimatio rei nella valutazione del danno aquiliano ed estensione della tutela ai non domini”, IURA, No 43, 1992, pp 244 y Valentino, Mario, "Del danno aquiliano al dannegiamento", LABEO, N 39, 1993, pp 259 y ss.

43 Valditara, Superamento dell'aestimatio ..., cit n. 38, pp 15 y ss.

$44 \quad$ Según el pasaje: "Inde Neratius scribit, si servís heres institutos occisus sit, etiam hereditatis aestimationem venire" ("por eso escribe Neracio que, si hubiera sido muerto un esclavo instituido, se computa también el valor de la herencia").

$45 \quad$ Señala el texto: "Aestimatio autem perempti non eadem in utriusque persona fiet: nam qui prior vulneravit tantum praestabit quanto in anno próximo homo plurimi fuerit repetitis ex die vulneris trecentum sexaginta 
Contra esta corriente neraziana, Valditara analiza luego la tesis de Sexto Pedio, jurista que vivió probablemente en el siglo II d.C., cuyo pensamiento queda muy claro en el pasaje recogido por Paulo, en D. 9, 2, 33pr:"46 "Si servum meum occidisti, non affectiones aestimandas esse puto, veluti si filium tuum naturalem quis occiderit quem tu magno emptum velles, sed quanti omnibus valerte. Sextus quoque Pedius ait pretia rerum non ex affectione nec utilitate singulorum, sed communiter fungi: itaque eum, qui filium naturales possidet, non eo locupletoriem esse, quod eum plurimo, si alius possideret, redempturus fuit, nec illum, qui filium alienum possideat, tantum habere, quanti eum patri vendere posset. in lege enim Aquilia damnum consequimur: et amisisse dicemur, quod aut consequi potuimus aut erogare cogimur" ("Si mataste a mi esclavo, opino que no se ha de estimar el valor de afección, como si alguien hubiese matado a tu hijo natural que tú querías comprar a gran precio, sino solo lo que valiese a gran precio, sino sólo por lo que valiese para todos. Dice también Sexto Pedio que los precios de las cosas son evaluados, no por la afección o la utilidad de personas concretas, sino de un modo general. Así pues, el que posee a su hijo propio no es más rico por el hecho de que habría que redimirlo a gran precio si otro lo poseyera, ni aquel que posea un hijo ajeno tiene el importe en que podría venderlo a su padre. Porque en la ley Aquilia conseguimos el daño, y decimos que se perdió o lo que pudimos conseguir o lo que fuimos obligados a gastar").

Pero especialmente en el pasaje del D. 35, 2, 63pr Pedio refuta la inclusión del valor de la

quinque diebus, posterior in id tenebitur quanti homo plurimi venire poterit in anno proximo quo vita excessit, in quo pretium quoquis hereditatis erit. eiusdem ergo servi occisi nomine alius maiorem alius minorem aestimationem praestabit, nec mirum, cum uterque eorum ex diversa causa et diversis temporibus occidisse nomine intellegatur. Quod si quis absurde a nobis haec constitui putaverit, cogitet longe adsurdius constitui neutrum lege Aquilia teneri aut alterum potius, cum neque impunita maleficia ese oporteat nec facile constitui possit uter potius lege teneatur. Multa autem iure civile contra rationem disputandi pro utilitate communi recepta esse innumerabilibus rebús probari potest: unum interim posuisse contentus ero. Cum plures trabem alienam furandi causa sustulerint quam singuli ferre non possent, furti actione omnes teneri existimantur, quamvis subtili ratione dici possit neminem eorum teneri, quia neminem verum sit eam sustulisse" ("Pero no se hará la misma valoración del muerto respecto a uno y otro. Porque el que primeramente hirió pagará tanto cuanto más haya valido el esclavo el año próximo contados trescientos sesenta y cinco días desde el día de la herida. El último estará obligado al mayor precio que pudiese ser vendido el esclavo en el año inmediato a aquel en que murió, en lo que se incluirá también el precio de la herencia. Por tanto, por el mismo esclavo muerto uno pagará mayor y otro menor estimación, y no es de admirar, porque se entiende que el uno y el otro mataron al esclavo por distinto acto y en momentos distintos. Pero si alguien pensara que sentamos una doctrina absurda piense que mucho más absurdo sería que ni uno ni otro quedasen obligados por la ley Aquilia, o que quedase obligado preferentemente uno, no debiendo quedar impunes los delitos, ni pudiéndose determinar fácilmente cuál de los dos preferentemente está obligado por la ley. Pueden probarse con innumerables ejemplos que, por la utilidad común, se admiten en derecho civil muchas cosas que pueden ser discutidas por la razón; me contentaré con haber expuesto un ejemplo. Cuando varios hubiesen sustraído por hurto una viga ajena que uno solo no podía llevar, se estima procedente que todos queden obligados por la acción de hurto, aunque apurando el razonamiento pueda decirse que ninguno de ellos queda obligado porque es verdad que ninguno la sustrajo”). Se refiere a estas dos corrientes también MacCormack, Aquilian Studies..., cit n. 18, pp70-71. 
Los requisitos de la lex Aquilia, con especial referencia al daño.

Lecturas desde las distintas teorías sobre el capítulo tercero.

herencia dentro del cálculo del más alto valor del esclavo dentro del año anterior a la muerte. ${ }^{47}$ Tanto Valditara como MacCormack indican que Pedio no adoptó una decisión de daños diferente a la declarada por Juliano, sino que en el caso concreto no parece justo incluir en el valor del esclavo el precio de la herencia. ${ }^{48}$

Otro texto que comenta el autor es el pasaje Gayano 3,212.49 Según Valditara, este pasaje resuelve en sentido similar al criterio de Neracio y Juliano, que el autor denomina del precio formal, en el sentido que Gayo autoriza a liquidar el precio del cuerpo más el suplemento que haya lugar, según las circunstancias. El método es idéntico al propuesto por Neracio para la muerte del esclavo heredero. Como indica el autor, el pasaje de Gayo aparece también en parte en el texto de Paulo, en D. 9, 2, 22, $1 .^{50}$

Finalmente, nos parece que para las pretensiones de este trabajo, bastará con citar brevemente otros dos pasajes largamente analizados por Valditara, atribuidos a Juliano e informados por Ulpiano. Nos referimos al D. 9, 2, 23, 1 y D. 9, 2, 23, 2. ${ }^{51}$ En cuanto al primero, Valditara da

$47 \quad$ Según el texto: "Pretia rerum non ex affectu nec utilitate singulorum, sed communiter funguntur. nec enim qui filium naturalem possidet tanto locupletior est, quod eum, si alius possideret, plurimo redempturus fuiste. sed nec ille, qui filium alienum possidet, tantum habet, quanta eum patri vendere potest, nec exspectandum est, dum vendat, sed in praesentia, non qua filius alicuius, sed qua homo aestimatur. eadem causa est eius servi, qui noxam nocuit: nec enim delinquendo quisque pretiosior fit. sed nec heredem post mortem testatoris institutum servum tanto pluris esse, quo pluris venire potest, Pedius scribit: est enim absurdum ipsum me heredem institutum non esse locupletoriem, antequam adeam, si autem servus heres institutus sit, statim me locupletoriem effectum, cum multis causis accidere possit, ne iussu nostro adeat: adquirit nobis certe cum adierit, esse autem praeposterum ante nos locupletes dici, quam adquisierimus".

48 En lo que toca a Valditara, Superamento dell'aestimatio..., cit n. 38, p 45, la decisión de Pedio se debe sólo a la particularidad de caso: "es cioè al fatto specifico per cui anche se lo schiavo non fosse stato ucciso non poteva considerarsi certo che avrebbe adito”. En cuanto a MacCormack, Aquilian Studies..., cit n. 18, p 71, sus argumentos son muy similares.

$49 \quad$ Según el pasaje: "Nec solum corpus in actione huius legis aestimatur; sed sane si servo occiso plus dominus capiat damni quam pretium servi sit, id quoque aestimatur, velutti si servus meus ab aliquo heres institutus, antequam iussu meo hereditatem cerneret, occisus fuerit; non enim tantum ipsius pretium aestimatur, sed et hereditatis amissae quantitas. Item si ex gemellis vel e comoedis vel ex symphoniacis unus occisus fuerit, non solum occisi fit aestimatio, sed eo amplius id quoque conputatur, quod ceteri qui supersunt depretiati sunt. Idem iuris est etiam si ex pari mularum unam vel etiam ex quadrigis equarum unum occiderit" ("No solamente se estima en la acción de esta ley el valor corporal, sino que, si con la muerte del esclavo recibe el dueño mayor perjuicio que el precio del esclavo, también ha de entrar esto en la estimación, como por ejemplo si mi esclavo, instituido heredero por alguien, fuera muerto antes de que por aprobación mía aceptara la herencia; no solo se estima el precio del propio esclavo, sino también el valor de la herencia que se ha perdido. Igualmente si mataras a uno de los comediantes, gemelos o músicos, no sólo se hace estimación del que haya muerto, sino que además se calcula en cuánto fueron depreciados los que quedaran. Lo mismo, si muriera una de las mulas de una yunta, o uno de los caballos de una cuadriga").

50 Valditara, Superamento dell'aestimatio..., cit n. 38, pp 62 y ss.

$51 \quad$ Según el primero: “Iulianus ait, si servus liber et heres esse iussus occisus fuerit, neque legitimum actione lege Aquiliae hereditatis aestimationem consecuturum, quae servo competere non potuit: quae sententia vera est pretii igitur solummodo fieri aestimationem, quia hoc interesse solum substituti videretur: ego autem puto nec 
cuenta de la diferencia de opinión entre Juliano y Ulpiano, pues mientras el primero reducía la liquidación al cuerpo del esclavo, el segundo incluso excluía esta posibilidad. Agrega que Juliano no hace más que seguir el criterio sustentado por él mismo en 51,2.52 En lo que atañe al segundo de los textos, Juliano haría una distinción: si el esclavo falleció después del testador, la condición de ser manumitido falla y debe incorporarse en el valor del esclavo el valor de la herencia; por el contrario, si éste es asesinado en vida del testador, el valor de la herencia no puede ser contabilizado. ${ }^{53}$

pretii fieri aestimationem, quia, si heres esset, et liber esset" ("Juliano dice que si hubiese sido muerto un esclavo que se manumitió en el testamento y se nombró heredero, ni el sustituto ni el legítimo habrá de conseguir con la acción de la ley Aquilia el valor de la herencia que no pudo competer al esclavo. Tal opinión es cierta. Por consiguiente, sólo se estima su precio porque únicamente éste se considera de interés para el sustituto. Sin embargo, yo creo que ni siquiera se hace estimación del precio, porque si fuese heredero sería también libre”). En lo que respecta al segundo: "Idem Iulianus scribit, si institutus fuero sub condicione si Stichum manumisero et Stichus sit occisus post mortem testatoris, in aestimationem etiam hereditatis pretium me consecuturum: propter occisionem enim defecit condicio: quod si vivo testatore occisus sit, hereditatis aestimationem cessare, quia restrorsum quanti plurimi fuit inspicitur" ("El mismo Juliano escribe que si yo hubiese sido instituído heredero bajo la condición "si yo manumitiese a Estico" y Estico hubiera sido asesinado después de la muerte del testador, habrá de conseguir también en la estimación el valor de la herencia ya que la condición falló por la muerte. Pero si hubiera sido muerto en vida del testador, cesa la estimación de la herencia porque el valor máximo se considera retrospectivamente").

52 Valditara, Superamento dell'aestimatio..., cit n. 38, pp 69-79. Según el autor, la regla de Ulpiano se debe a una distinta concepción de la valoración del daño. Según MacCormack, Aquilian Studies..., cit n. 18, p 73: "Neither Iulian nor Ulpian can be shown to have applied a standart of assessment based upon the "interest" of the dominus. Interpretations of the text which attribute to Iulian or Ulpian a decision based upon the notion of "interest", and particulary those which use this notion as a criterion for interpolation appear to me to be misconceived".

53 Para Valditara, Superamento dell'aestimatio..., cit n. 38, pp 101-108, por diversas razones de texto analizadas, es muy probable que se trate de un texto interpolado y que varias de las frases utilizadas en el pasaje, como in aestimationem etiam hereditatis pretium me consecuturum le hace pensar que el texto más bien pertenece a Ulpiano. Además, ya desde un punto de vista sustantivo, el autor plantea que el texto no parece conciliar con la idea de Juliano expresadas en D. 9, 2, 51, 1, en cuanto que consienta en liquidar conjuntamente el precio del esclavo con el valor de la herencia. Contrariamente, MacCormack, Aquilian Studies..., cit n. 18, p 73. Este autor opina que las dificultades del texto puede ser removidas si se compara con el anterior, es decir, 23,1. A pesar del hecho que el esclavo pueda ser libre sólo si es manumitido, el caso es esencialmente similar al considerado en 23,1. En suma, según este autor, Juliano hace una distinción. Si es asesinado después de la muerte del testador, el valor de la herencia puede ser tratado como un elemento en el más alto valor del esclavo dentro del año previo. Cuando el esclavo es asesinado antes de la muerte del testador, el más alto valor dentro del año no puede incluir el valor de la herencia. La razón de la diferencia es que en el último caso, el dueño en los hechos obtiene la herencia. Un extenso comentario sobre ambos textos se encuentra en Rodger, Alan, "Damages for the Loss of an Inheritance" A.A.V.V. Essays in Legal History for David Daube, Edimburgo: Scottisch Academic Press, 1974, pp 289 y ss, quien sobre este punto sostiene que en 23,1, el curso normal de los acontecimientos requerían que el esclavo fuera muerto antes que el substituto pueda heredar, mientras que en 23,2 lo que se habría previsto era que el demandante podría primero haber cesado la propiedad de Estico por manumitirlo. El punto esencial es que en ambos textos el demandante podría no tener la propiedad del esclavo. Señala, finalmente, que Juliano otorga la acción directa en ambos casos sólo cuando el esclavo fallece después del testador; en cambio, si fallecía antes, la acción no estaba disponible. La razón dada en 23,2 es que el valor máximo se considera retrospectivamente, pero el autor entiende que se trata de un falso argumento. La verdadera razón para negar la acción en el caso que la muerte del esclavo se produzca antes de la muerte del testador es que no se han producido daños en el momento. 
Los requisitos de la lex Aquilia, con especial referencia al daño.

Lecturas desde las distintas teorías sobre el capítulo tercero.

Desde luego, son muchísimos más los textos analizados por Valditara, a los que nos referiremos por la extensión y pretensiones de este trabajo, pero si es importante señalar que todos ellos marcan una evolución en la valoración o cuantificación del daño. Como conclusión de este primer período y como consecuencia de su concepción del tenor originario de la norma, contrario, como hemos visto, a la tesis de Daube, deduce que para la jurisprudencia hasta el último decenio del siglo I d.C., el pretium rei, liquidable como remedio aquiliano, se identifica con el pretium corporis. A partir de finales del siglo I d.C. se inició una interpretación más favorable al dañado, considerando no sólo el valor corporis de acuerdo con el valor de mercado, sino además las ventajas que dicho bien garantizaba o había garantizado al dueño, introduciendo el criterio del interés, que en un comienzo significó sólo una suma, una utilitas que se adjunta al valor del corpus, criterio que el autor denomina como "el precio formal" y que viene acompañado del otorgamiento de acciones in factum, revelando la inexistencia de un criterio idóneo para la valoración de los intereses. ${ }^{54}$

Posteriormente, el criterio del precio formal habría mutado por una más amplia consideración de los intereses de la víctima, traduciéndose en el principio del id quod interest. El autor señala como punto de inflexión el pasaje del D. 9, 2, 21, 2, de Ulpiano. ${ }^{55}$ Es decir, que va ser la jurisprudencia posterior a Juliano la que va a evolucionar para desarrollar el principio del id quod interest, que va ser obra final de la jurisprudencia imperial, de los siglos I a III d.C. ${ }^{56}$

54 Valditara, Superamento dell'aestimatio ..., cit n. 39, pp 176-178. En el mismo sentido, Talamanca, Mario, Istituzioni di Diritto Romano, Milán: Giuffrè Editore, 1990, p 628. Sobre esta paulatina evolución de la aestimatio rei, mediante la interpretación de los verbos de la ley, D'ors, cit n. 8, p 435 señala como con Neracio, Javoleno y Juliano se inicia una interpretación de los verbos en la que la aestimatio rei va a tener en cuenta no sólo el valor real de la cosa perdida o deteriorada, sino también el lucro indirectamente perdido, estimado siempre objetivamente. Sobre la valoración del "precio formal" y su distinción del principio id quod interest puede consultarse a Castresana, cit n. 9, p 36, quien explica que la evolución de los juristas clásicos irá desde el originario pretium corporis del texto legal hasta el renovado quanto homo venire poterit de Juliano en D. 9, 2, 51, 2, hasta llegar al pretium servi utilizado por Gayo en 3, 212.

55 Según el texto: "Sed utrum corpus eius solum aestimamus, quanta fuerit cum occideretur, an potius quanti interfuit nostra non esse occisum? et hoc iure utimur, ut eius quod interest fiat aestimatio” ("Pero ¿valoramos solamente su cuerpo en el valor que tuvo cuando fue muerto o más bien la cuantía de nuestro interés en que no hubiese sido muerto? Y seguimos la regla de estimar el interés”). En él, Ulpiano trata de sintetizar la disputa jurisprudencial entre los partidarios del pretium corporis y los de la utilitas domini. Como señala Castresana, cit n. 10, p 37, a propósito de este pasaje, como consecuencia, Ulpiano va a acordar la tutela ex lege Aquilia a sujetos lesionados en sus propios intereses, aunque sean non domini, en virtud de un nuevo criterio de estimación del daño. Albanese, Rencension critiche, cit n. 42, p 247, indica que causa perplejidad y dudas la distinción entre el precio formal y el principio id quod interest en la forma propuesta por Valditara, referido el primero a los juristas preseverianos, el segundo a los tardos clásicos, pues puede mostrarse un tanto forzada en aquellos juristas que parecen asumir ambos criterios.

56 Valditara, Superamento dell'aestimatio..., cit n. 38, pp 201 y ss. Nuevamente, el autor se dedica a un largo análisis de los textos para sustentar su conclusión. Algunos de los citados son bastante interesantes. Algunos de ellos son, por ejemplo, dos textos de Paulo. El primero en D. 9, 2, 12. En éste, cuando la "cosa" objeto del usufructo era un esclavo, Paulo estaba de acuerdo en otorgar la acción de la ley Aquilia. Según el texto: "Sed et si proprietatis dominus vulneraverit servum vel occiderit, in quo usus fructus mens est, danda est mihi ad 
Finalmente, nos parece preciso citar sobre esta materia las ideas de Jolowicz, quien plantea por primera vez la tesis que va a contradecir posteriormente Daube, es decir, que originariamente el capítulo tercero estaba referido a objetos inanimados y las conductas tipificaban sólo su destrucción total, de modo que obviamente la sanción de los 30 días estaba referida hacia el pasado. Desde luego los matices respecto de la hipótesis emparentada de Valditara también influyen en esta cuestión, donde ciertas discrepancias podrán anotarse, aún cuando sean menores.

exemplum legis Aquiliae actio in eum pro portione usus fructus, ut etiam ea pars anni in aestimationem veniat, qua nondum usus fructus meus fuit" ("También el nudo propietario hubiese herido o matado al esclavo sobre el que yo tengo el usufructo, debe dárseme contra aquél una acción a semejanza de la ley Aquilia, proporcional a mi usufructo, de modo que incluso aquella parte del año en el que el usufructo todavía no era mío se tenga en cuenta para calcular la estimación”). Una explicación sobre la originalidad del texto y las posibles interpolaciones, en cuanto a la inclusión de vulneravit puede encontrarse en Iliffe, John, "The usufructuary as plaintiff under the lex Aquilia according to the Classical jurists", RIDA, No 12, 1965, pp 342-344. De otra parte, en opinión de Natali, cit n. 3, p 113, el texto en análisis sugiere que el usufructuario debía excluir el importe del usufructo que ya había gozado, lo que parece ser una opinión mayoritaria desde hace bastante tiempo. Sobre esta cuestión, Ferrini, Contardo, La legitimazione attiva nell' “actio legis Aquiliae. Opere di Contardo Ferrini, Volumen Quinto, Milán: Ulrico Hoepli, 1930, pp 207-209.

En el segundo, D. 9, 2, 22pr: "Proinde si servum occidisti, quem sub poena trandendum promisi, utilitas venit in hoc iudicium" ("Por consiguiente, si mataste a un esclavo que yo prometí entregar bajo pena convencional, mi interés < por librarme de la pena> se computa en esta acción”). Según VALDITARA, Superacento dell'aestimatio rei..., cit, p 226, más allá de las discusiones sobre la genuidad de los textos en cuestión, ambos textos muestran como el autor prescinde del pretium rei, valiéndose del criterio de la aetimatio utilitatis.

Luego de analizar otros texto paulinos, el autor centra su estudio en el pasaje de Labeón, informado por Ulpiano, en D. 9, 2, 29, 3: "Item Labeo scribit, si, cum vi ventorum navis impulsa esset in funes anchorarum alterius et nautae funes praecindissent, si nullo alio modo nisi praecisis funibus explicare se potuit, nullam actionem dandam, idemque Labeo et Proculus et circa retia piscatorum, in quae navis piscatorum inciderat, aestimarunt, plane si culpa nautarum in factum esset, lege Aquilia agendum sed ubi damni iniuria agitur ob retia, non piscium, qui ideo capti non sunt, fieri aestimationem, cum incertum fuerit, an caperentur indemque et in venatoribus et in aucupibus probandum" ( "Escribe también Labeón que si la nave hubiese sido impelida por la fuerza de los vientos contra cuerdas de anclas de la otra y los marineros hubiesen cortado las cuerdas, si sólo cortando las cuerdas pudo desenredarse aquella nave, no hay que dar acción alguna. Y lo mismo estimaron Labeón y Próculo acerca de redes de los pescadores en las que había caído un barco de pesca. Por supuesto que si ello hubiese ocurrido por culpa de los marineros, puede demandarse por la ley Aquilia. Pero cuando se demanda por daño injusto por las redes, no se hace la estimación de los peces que por tal motivo no se pescaron, ya que fue incierto si se habrían pescado. Y lo mismo es cierto respecto a cazadores y cetreros"). Finalmente, cita el texto de Ulpiano en D. 9, 2, 23, 6: "In summa omnia commoda, quae intra annum, quo interfectus est, pretiosiorem servum facerent, haec accederé ad aestimationem eius dicendum est" ("En breve, hay que decir que todas las ventajas que harían más valioso el esclavo dentro del año en fue muerto se computan en la estimación”).

En suma, luego de resumir los diferentes planteamientos doctrinarios sobre el problema del principios id quod interest (pp 266-276), el autor sostiene que el antecedente lógico o paso previo del principio analizado jugo el concepto de utilitas, que hemos visto en pasajes precedentemente citados. Explica como el sistema de resarcimiento de la lex Aquilia y la interpretación rígida de sus verbos, impidieron implementar el resarcimiento del interés de la víctima, de modo que los capítulos primero y tercero sólo permitían considerar el valor del corpus. El paso siguiente fue la ampliación para incorporar lo que el autor denomina el "precio formal" y luego, la jurisprudencia pre-severiana dará un paso más recurriendo al criterio de la utilitas, que implica el valor comprensivo del objeto del resarcimiento, independiente del pretium corpori. 
Los requisitos de la lex Aquilia, con especial referencia al daño.

Lecturas desde las distintas teorías sobre el capítulo tercero.

Así, es medianamente lógico que este autor piense que el principio del interés surgirá en los casos de pérdida parcial, una vez que se incorporaron los deterioros y los daños a cosas animadas, siendo necesario un nuevo método de valoración. Agrega que Labeón ya estaba completamente familiarizado con el principio del interesse, pero que necesitaba casos de injusticia flagrante para aplicarlo. Era precisamente la sanción de la ley Aquilia, con su carácter temporal, la que habría impedido el desarrollo del principio del interés. ${ }^{57}$

De esta manera, el principio del más alto valor de la cosa sería incompatible con el del interesse. Agrega que -y de ahí anotamos la diferencia con la construcción de Valditara- que una vez introducido el principio del interés éste no desplazó el viejo principio establecido en la ley, existiendo muchos casos en los que se siguió discutiendo la aplicación de la regla temporal, aunque agrega que en un gran número de casos aplicar un principio u otro no conducía a diferencias prácticas.

En definitiva, según el autor, los juristas romanos nunca trabajaron en la elaboración de una teoría consistente de los daños, porque dicho desarrollo fue obstaculizado por la regla arcaica y porque nunca lograron distinguir claramente la diferencia entre valor de mercado y el valor para el propietario (o valor de afección o de interés). Agrega que si bien es cierto el valor de mercado tenía una precisión terminológica, no ocurrió lo mismo con el valor del interesse. Este análisis le lleva a distinguir tres tipos de casos que pueden ser reconocidos en las fuentes: a) aquellos en los cuales no se contempla la cuestión del interés y donde simplemente se toma en cuenta el valor de mercado, de acuerdo con la regla temporal. Desde luego, este grupo de casos podrían haber operado en las hipótesis de pérdida total. Señala como ejemplos el D. 23, 3, 5, 7 y D. 9, 2, 51, 2. ${ }^{58}$

El segundo grupo de casos se adopta el principio del interesse, en hipótesis de daños parciales y destrucción de documentos y títulos de crédito, como en D. 9, 2, 22pr o lo casos de destrucción de documentos, en D. 9, 2, 40-42, como ejemplos del principio del interés; y, D. 9, 2, 29, 3 en caso de pérdida o destrucción parcial. ${ }^{59}$ Por último, en el tercer grupo de casos entiende el

Jolowicz, cit n. 6, p 225. En verdad señala el autor una interesante cuestión y es que la expresión quati ea res fuit tenía en Derecho romano un significado ambiguo, pudiendo significar el valor de la cosa o el costo de las circunstancias. Los juristas romanos, por su parte, habrían interpretado en uno u otro sentido el texto y cita dos opiniones de Ulpiano en D. 50, 16, 193 y 39, 2, 4, 7 en las que interpreta la expresión como valor de la cosa e id quod interest respectivamente, pero que en la lex Aquilia dicho significado ambiguo no se habría presentado al establecer la sanción con un carácter temporal.

58 Jolowicz, cit n. 6, pp 226-227.

59 Si uno es coherente con la tesis de Jolowicz debería esperar que en tales casos, en los que se asume el principio del interés, especialmente cuando se trata de pérdidas parciales, se corresponda con el desarrollo decretal de las acciones de la ley, es decir, deberíamos esperar el otorgamiento de acciones in factum o útiles. Lo curioso es que en los casos que cita el autor como de pérdida parcial, como cuando las redes pesca se rompen, los juristas entendieron que debía ser otorgada una acción directa, la actio legis y no una acción decretal. Y también en los casos en los que documentos testamentarios son borrados, los juristas otorgaron la acción directa, incluso aún ampliando el ámbito de aplicación del verbo rumpere por corrumpere. 
autor que hay un choque de ambos principios y un intento de conciliarlos, donde el principio del interés forma parte del más alto valor y es incluido en la regla temporal. Cita como ejemplo el pasaje del D. 9, 2, 23, 2, al que nos hemos referido. ${ }^{60}$

\section{Conclusiones}

Hemos intentado reseñar brevemente los requisitos que según la doctrina moderna exigió la lex Aquilia para la configuración del delito de damnum iniuria datum. Pero esencialmente, hemos intentado repasar tales requisitos, especialmente el daño, desde las distintas lecturas del capítulo primero, que corresponden, con los variados matices que hemos reflejado, a dos maneras distintas de entender la ley.

Una visión, tradicional, considera que le lex Aquilia tenía un carácter o naturaleza claramente penal. En esta perspectiva, se reafirma el principio corpore corpori como originario en la ley y como un resabio del carácter primitivo de la acción, se contempla una plena equivalencia entre los capítulos primero y tercero y, por tanto en este último, se piensa que la sanción estaba referida hacia el pasado e incorporaba o bien sólo objetos inanimados (como en las ideas de Jolowicz-Cannata) o bien una cláusula general de daños (como en Valditara). Luego, esta comprensión influye sobre la iniuria, que se desvincula completamente de los delitos de iniuria de las XII Tablas, como actos de violencia.

Algunos extraen consecuencias para el terreno de la culpa (como Rotondi y Arangio Ruiz), pues precisamente el principio corpore corpori habría obstado la incorporación de la culpanegligencia en el sistema de la lex Aquilia, lo que sólo se habría conseguido en época justinianea, tesis que como hemos visto fue refutada posteriormente. En lo que toca al daño, especialmente, este punto de vista considera que la ley alcanzó un carácter resarcitorio paulatinamente, de modo que el principio id quod interest obedeció a un desarrollo posterior, valorándose solamente el objeto dañado para el propietario en un comienzo, aunque hemos advertido las diferentes aproximaciones de Valditara, Jolowicz y, en menor medida MacCormack y Albanese.

La otra visión, que arranca con Daube, plantea una lectura contraria. La ley se visualiza como un régimen de resarcimiento de daños, cuyo carácter penal era más bien instrumental (aunque hay otros que han sostenido posiciones similares, aún cuando no se correspondan con sus lecturas del capítulo tercero y de los requisitos del daño).

Desde esta perspectiva, Daube niega la existencia del principio corpore corpori, el que considerará como un desarrollo medieval, se niega la equivalencia entre los capítulos primero 
y tercero, considerando que el último comprendía sólo las lesiones y daños parciales a seres animados, por lo cual la sanción estaría referida hacia el futro (verbo erit, utilizado en D. 9, 2, 27, 5). De este modo, el damnum sería un concepto utilizado sólo en el capítulo tercero, lo que importaría la incorporación, desde el origen de la ley, del principio id quod interest. Dicho principio se habría desarrollado posteriormente, a partir de Neracio, para el capítulo primero. Como dice Cannata, este sector doctrinal construye todo un régimen aquiliano de hechos que producen deterioro. ${ }^{61}$

Finalmente, la corriente desarrollada por Daube llevará a que algunos de sus seguidores establezcan plena coincidencia entre los delitos de iniuria de las XII Tablas y el capítulo tercero de la ley; en concreto, que los verbos urere, frangere, rumpere derivarían de los delitos decenvirales y, como consecuencia, la iniuria elemento del delito de damnum se visualiza originariamente como acto de violencia, aunque la tesis ha sido defendida por autores que no se identifican con la tesis de Daube, como Kelly o La Rosa. 